\title{
1 Study on heat transfer process during leaks of high pressure argon through a realistic crack
}

4 aSchool of Aerospace Engineering, Tsinghua University, Beijing 100084, People's Republic of 5 China

6 bshool of Mechanical and Aerospace Engineering, Nanyang Technological University, 50 7 Nanyang Avenue, Singapore 639798.

$8 \quad{ }^{*}$ Corresponding author. Tel. +86 18810569561. E-mail address: aigang2000@ gmail.com

Abstract:

11 This paper proposes a method for simulating the heat transfer process of high pressure argon 12 gas leaking through a narrow crack which causes the Joule-Thomson cooling effect (JT cooling 13 effect). A once-through (decoupled) model was developed to firstly calculate the gas pressure 14 drop at different crack depth, followed by the temperature drop. A MATLAB code was also 15 developed to iteratively calculate the properties of leaking gas in a crack which was fitted as 16 formula as boundary conditions in heat transfer simulation in COMSOL program. The simulated 17 lowest temperature of the test plate in the vicinity of the crack is $13.8{ }^{\circ} \mathrm{C}$ after decreasing from 18 the temperature of $30{ }^{\circ} \mathrm{C}$ with initial argon gas pressure of 91 bar. An experiment test rig 19 designed and tested under the same conditions showed a good agreement between the simulation 20 and experiment at the obtained lowest temperature in the test plate. The method is useful for 21 predicting the lowest temperature in the vicinity of the crack caused by the JT cooling effect.

22 Keywords: cracks, leakage, Joule-Thomson cooling effect, heat transfer simulation 


\begin{tabular}{|c|c|}
\hline Nomenclatur & \\
\hline Latin charactel & \\
\hline$A$ & cross-section area, $\mathrm{m}^{2}$ \\
\hline$a_{0}, a_{1}, a_{2}$, and $a_{3}$ & empirical constants of gas property dependent \\
\hline$C_{p}$ & heat capacity at constant pressure, $\mathrm{J} /(\mathrm{kg} \cdot \mathrm{K})$ \\
\hline$D$ & diameter of microchannels, $\mathrm{m}$ \\
\hline$D_{\mathrm{e}}$ & equivalent diameter, $\mathrm{m}$ \\
\hline$d p$ & pressure drop per depth increment into the crack, $\mathrm{Pa}$ or bar \\
\hline$f$ & friction factor \\
\hline$H$ & Enthalpy, J \\
\hline$h$ & heat transfer coefficient, $\mathrm{W} /\left(\mathrm{m}^{2} \cdot \mathrm{K}\right)$ \\
\hline$L$ & characteristic length, $\mathrm{m}$ \\
\hline M & molar mass, $\mathrm{g} / \mathrm{mol}$ \\
\hline$N_{u}$ & Nusselt number \\
\hline$N u_{G n}$ & Gnielinski modified Nusselt number \\
\hline$P$ & wetting perimeter, $\mathrm{m}$ \\
\hline$p$ & pressure, $\mathrm{Pa}$ or bar \\
\hline$P_{r}$ & Prandtl number \\
\hline$R_{e}$ & Reynolds number \\
\hline$R_{\text {eff }}$ & effective roughness, $\mathrm{m}$ or $\mu \mathrm{m}$ \\
\hline$R_{\text {glamp }}$ & $\begin{array}{l}\text { peak-to-trough amplitude of the global roughness contours for a sawtooth } \\
\text { geometry, equal to four times the global roughness } R_{\text {global, }} \mathrm{m} \text { or } \mu \mathrm{m}\end{array}$ \\
\hline$R_{\text {global }}$ & global roughness, $\mathrm{m}$ or $\mu \mathrm{m}$ \\
\hline$R_{\text {local }}$ & local roughness, $\mathrm{m}$ or $\mu \mathrm{m}$ \\
\hline$T$ & temperature, $\mathrm{K}$ or ${ }^{\circ} \mathrm{C}$ \\
\hline$t$ & crack through-wall thickness (or crack depth), $\mathrm{m}$ or mm \\
\hline$t_{\text {eff }}$ & effective crack through-wall thickness, $\mathrm{m}$ or $\mathrm{mm}$ \\
\hline$v$ & fluid velocity, $\mathrm{m} / \mathrm{s}$ \\
\hline$W_{c}$ & $\begin{array}{l}\text { crack opening displacement (or crack width) perpendicular to the through- } \\
\text { wall direction, } \mathrm{m} \text { or } \mathrm{mm}\end{array}$ \\
\hline
\end{tabular}




\begin{tabular}{|c|c|}
\hline$W_{\text {ceff }}$ & effective crack width perpendicular to the average flow direction, $\mathrm{m}$ or $\mathrm{mm}$ \\
\hline \multicolumn{2}{|c|}{ Greek characters } \\
\hline$\alpha$ & crack surface angle relative to the crack direction through wall, rad \\
\hline$\Delta \mathrm{p}$ & pressure loss, Pa or bar \\
\hline$\Delta$ pric & $\begin{array}{l}\text { frictional term of pressure loss during fluid flowing through a crack, Pa or } \\
\text { bar }\end{array}$ \\
\hline$\Delta$ pinert & inertial term of pressure loss during fluid flowing through a crack, Pa or bar \\
\hline$\Delta$ precirc & $\begin{array}{l}\text { recirculation term of pressure loss during fluid flowing through a crack, } \mathrm{Pa} \\
\text { or bar }\end{array}$ \\
\hline$\eta$ & dynamic viscosity, $\mu \mathrm{Pa} \cdot \mathrm{s}$ \\
\hline$\theta$ & average flow direction relative to the crack direction through-wall, rad \\
\hline$\lambda$ & thermal conductivity, $\mathrm{mW} \cdot \mathrm{m}^{-1} \cdot \mathrm{K}^{-1}$ \\
\hline$\lambda^{\mathrm{c}}$ & thermal conductivity critical enhancement, $\mathrm{mW} \cdot \mathrm{m}^{-1} \cdot \mathrm{K}^{-1}$ \\
\hline$\lambda^{0}$ & dilute gas thermal conductivity, $\mathrm{mW} \cdot \mathrm{m}^{-1} \cdot \mathrm{K}^{-1}$ \\
\hline$\lambda^{\mathrm{r}}$ & residual fluid thermal conductivity, $\mathrm{mW} \cdot \mathrm{m}^{-1} \cdot \mathrm{K}^{-1}$ \\
\hline$\mu \mathrm{JT}$ & Joule-Thomson coefficient, $\mathrm{K} / \mathrm{Pa}$ or ${ }^{\circ} \mathrm{C} / \mathrm{bar}$ \\
\hline$\hat{v}$ & specific volume (which is the reciprocal of density), $\mathrm{m}^{3} / \mathrm{kg}$ \\
\hline$\rho$ & fluid density, $\mathrm{kg} / \mathrm{m}^{3}$ \\
\hline
\end{tabular}

\section{Introduction}

Natural gas now plays an important strategic role in energy supply as global energy demand 3 rises. The price and environmental advantages render natural gas as one of the most acceptable 4 forms of energy. However, it is more difficult to transport and store gas than oil and therefore it 5 lagged behind oil for a considerable period. ${ }^{[2-4]}$ In natural gas transportation, large market 6 reserves mainly rely on Pipelined Natural Gas (PNG) and Liquefied Natural Gas (LNG) 7 transportation technologies. However, 30\% of the discovered gas is considered "stranded" 8 throughout the world. "Stranded" is defined as gas reservoir fractions that prevent their 9 development or optimal production from an oil or gas field as a result of their distance from the 
market, lack of transport economy or conversion technology. Neither PNG nor LNG

2 transportation technique can economically exploit these stranded gas reserves.

3 Compressed Natural Gas (CNG) transportation can be considered as a niche that will 4 supplement both PNG and LNG technologies for the monetization of stranded gas. The basic 5 idea of CNG is to compress the natural gas at pressures between 100 and $250 \mathrm{bar}$, and sometimes

6 chill it to lower temperatures (up to $-40{ }^{\circ} \mathrm{C}$ ). In CNG projects, the gas is stored in high pressure 7 piping or coils inside the CNG ships (up to 250 bar), therefore the reliability of pressure vessel 8 and careful design of CNG transport fleets are very important.

9 The critical technology to maintain the integrity of pressure vessels is the concept of leak10 before-break (LBB) ${ }^{[5-10]}$ The LBB technology applied in nuclear industry can be transplanted

11 into CNG systems, although there are significant differences. For CNG system with leakage on 12 the container wall, the temperature of leaking CNG will drop due to Joule-Thomson (JT) cooling 13 effect when CNG passes through the crack. This will chill the vessel wall in the vicinity of the

14 crack and reduce the fracture toughness of the wall. This may push the transition of previously 15 stable crack propagation to become critical. Therefore, it is necessary to assess the impact of the 16 JT cooling effect in cracks on the LBB approach and on the safety and reliability of pressure 17 vessels.

18 There are very few papers on this research topic. The challenges in this study are how to 19 develop a model to represent the JT effect in narrow and tortuous cracks and to evaluate the 20 pressure and temperature drop of leaking gas through cracks. Many factors such as crack 21 opening displacement, crack surface angle, crack turns, surface roughness and temperature 22 dependent properties of the gas critically affect the process. This paper presents an acceptable 23 crack model to calculate the temperature and heat transfer coefficient of leaking gas through a 24 crack and then simulate the metal temperature distribution in the vicinity of the crack.

\section{2. Summary of the experimental work}

26 An experimental study of the JT effect reported in $\mathrm{Ai}$ and $\mathrm{Ng}^{[11]}$ was conducted with argon 27 gas. Argon is safer as it is inert compared to flammable methane, the major constituent of natural 28 gas, and it possesses a similar JT coefficient to that of methane. ${ }^{[12-16]}$ A pressure vessel was 
1 designed and fabricated according to ASME Boiler and Pressure Vessel Code Section VIII 2 Division 1 and Section II Part $\mathrm{D}^{[17,18]}$ and a JT test system was set up as shown in Fig. 1. The 3 detailed dimensions of the pressure vessel are shown in Fig. 2. The key part in the experiment is 4 the data collection of temperature in the vicinity of the crack in the test plate. The test plate is 5 clamped between the upper and lower flanges of the pressure vessel. The thermocouple mounting locations on the test plate are shown in Fig. 3.

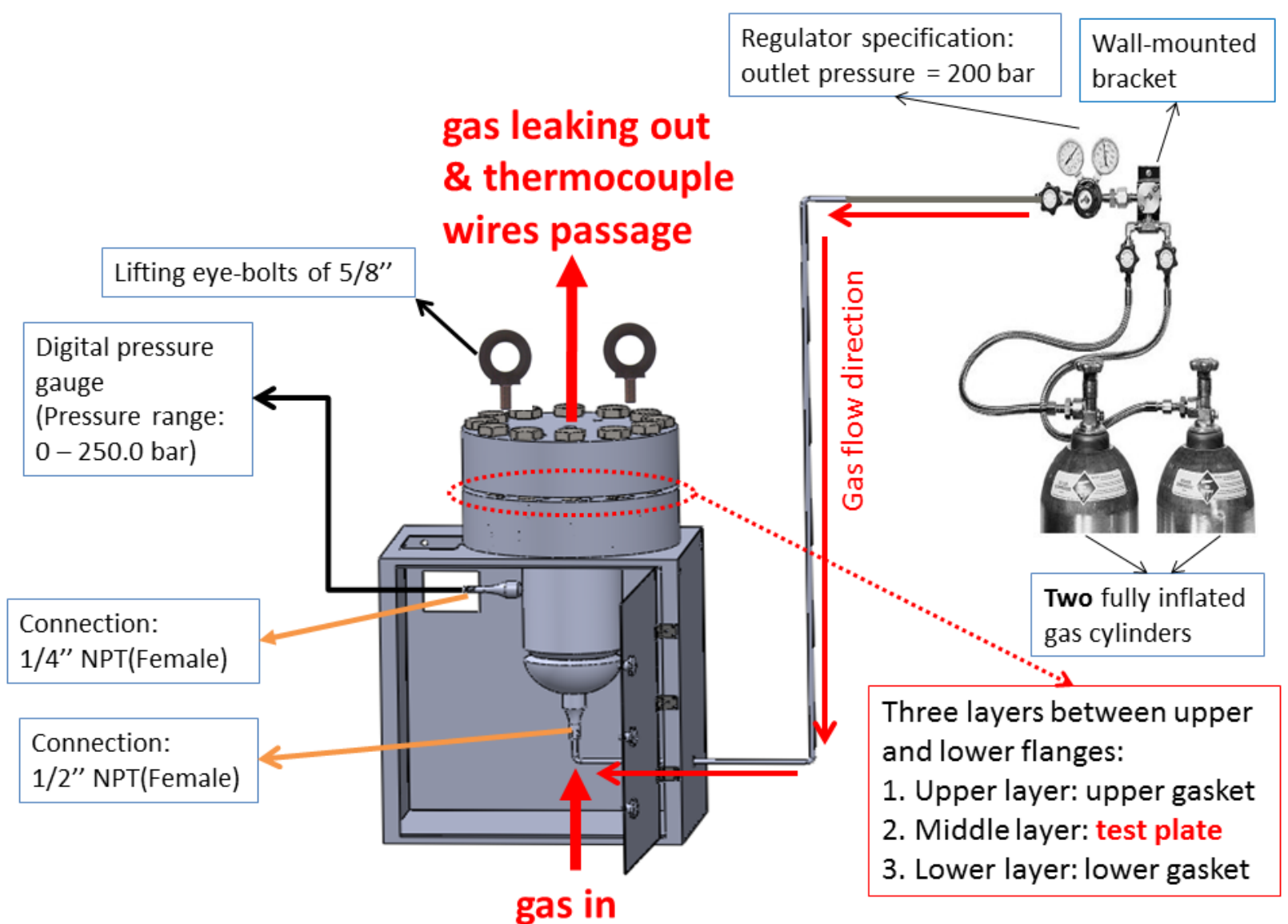

Fig. 1. Set-up of the JT test system. 


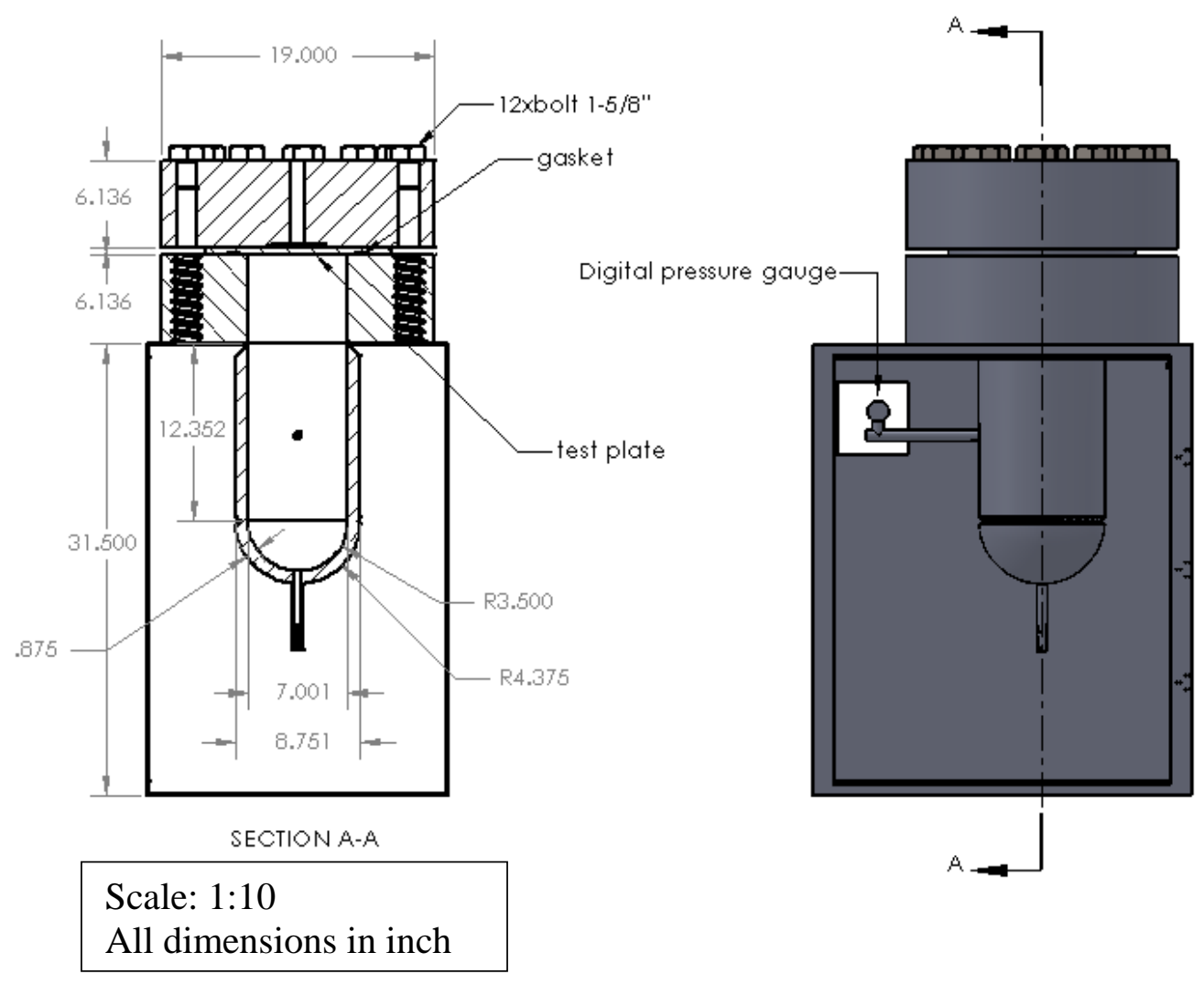

Fig. 2. Detailed dimensions of the pressure vessel.

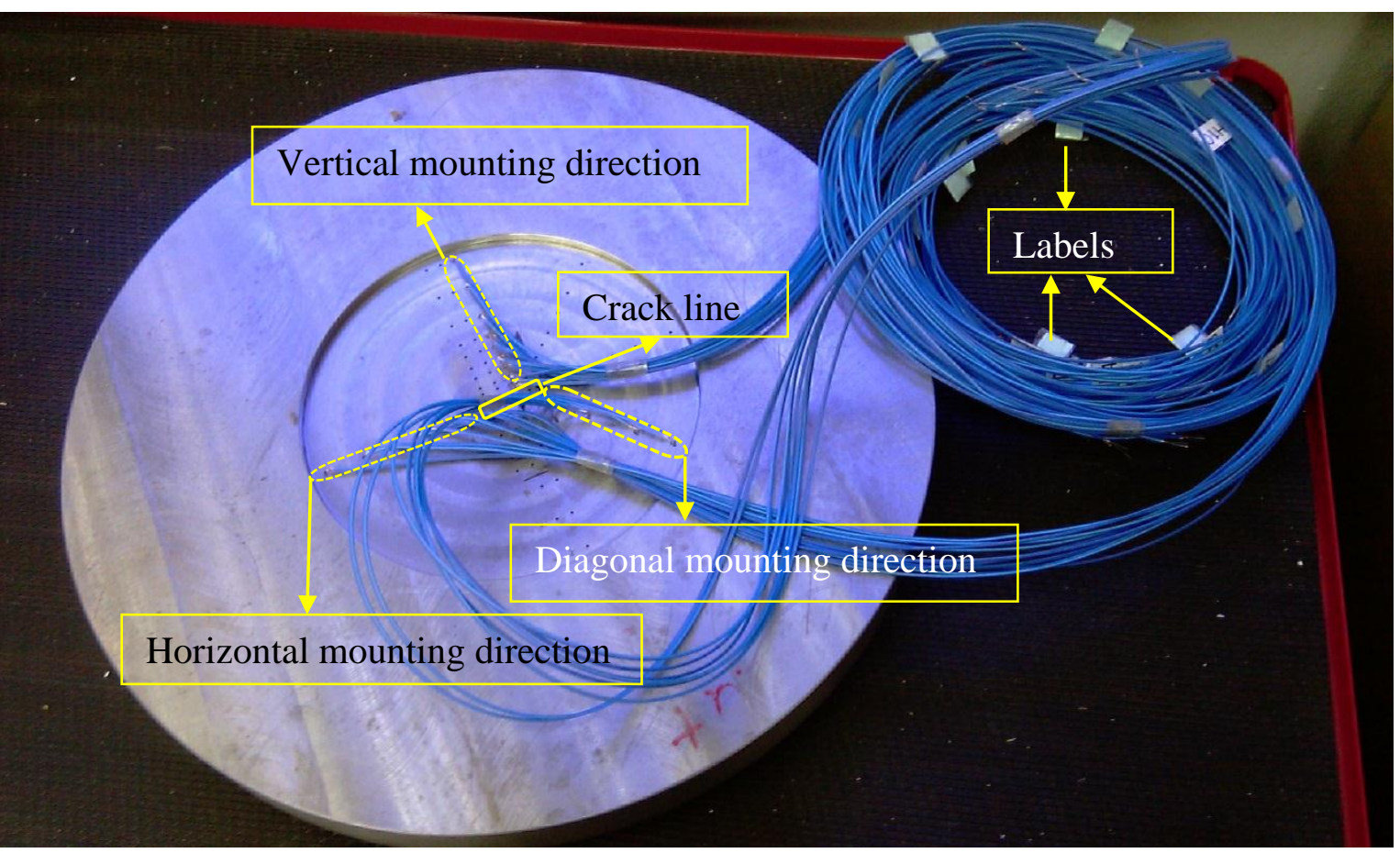

Fig. 3. Thermocouple mounting locations on the test plate. 
2 The test plate contains an artificial, but realistic crack which is made following the procedures

3 shown in Fig. 4. The liquid nitrogen quenching method was adopted in this research. The 4 cracked pieces were mated and welded together into the slot machined in the test plate. The 5 realistic crack-like leak path is shown in Fig. 5. The detailed dimensions of the test plate are 6 shown in Fig. 6.

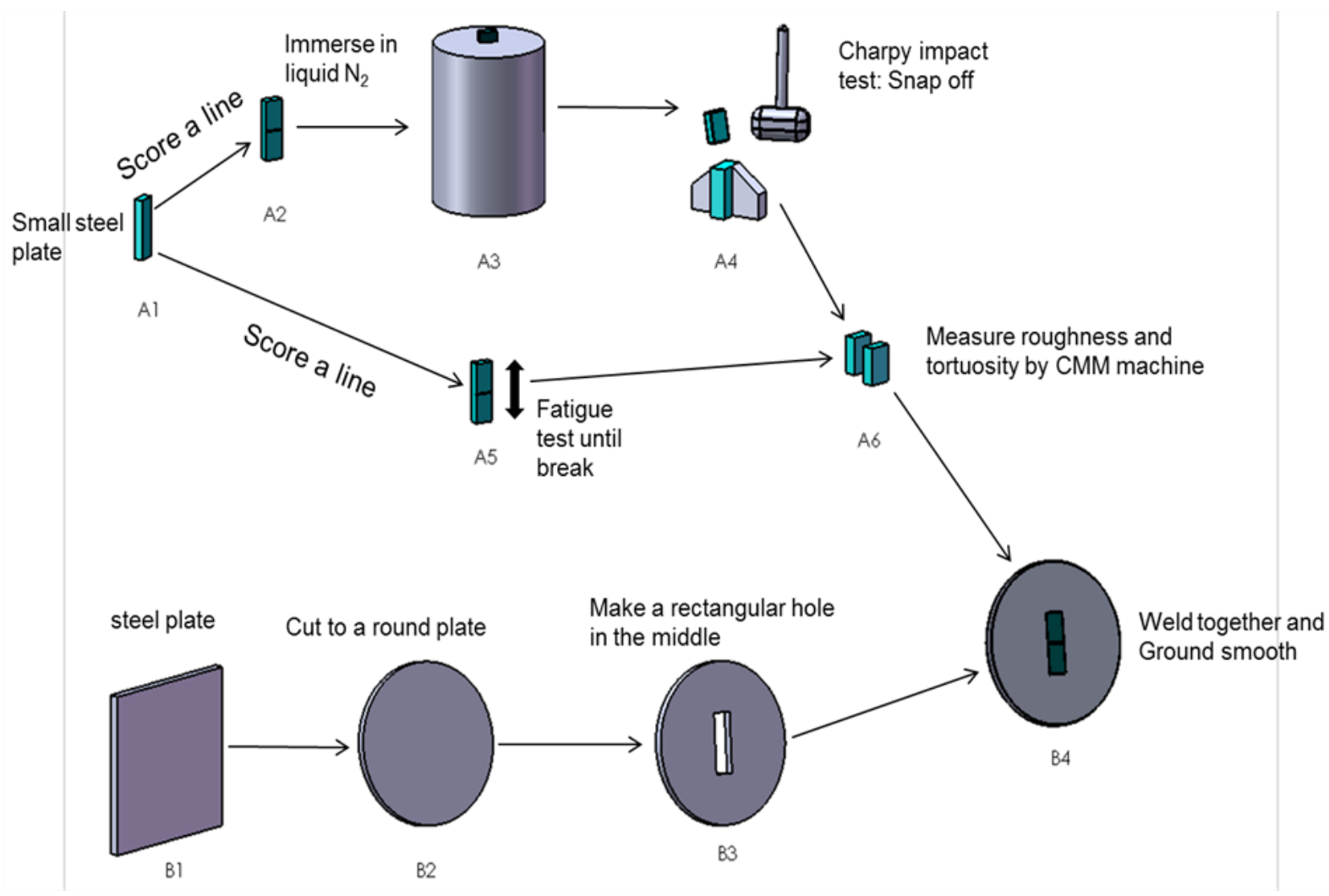

8 Fig. 4. Flow chart of the fabrication of test plate with a realistic through-thickness crack. 


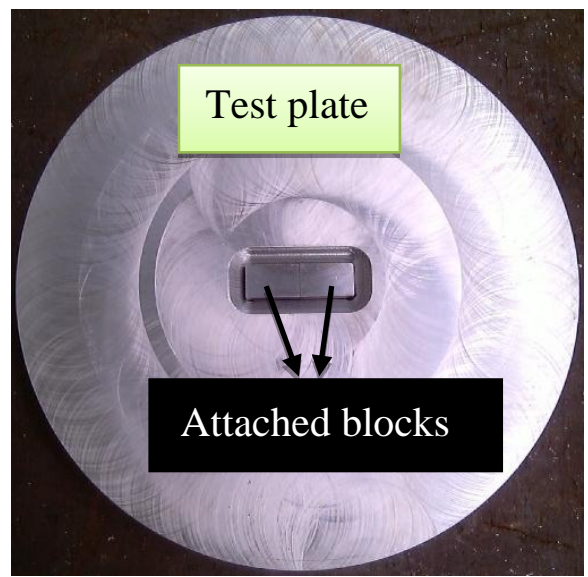

(a) The cracked test block placed into the test plate before welding

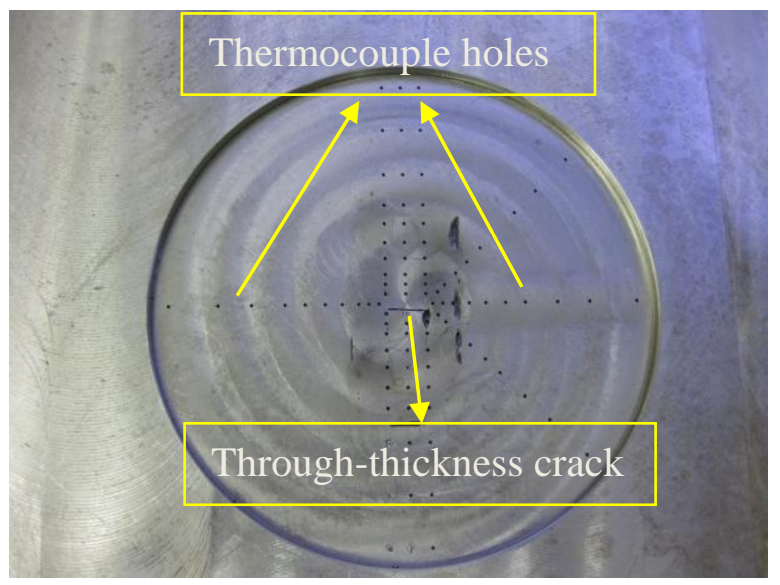

(b) The test blocks welded into the test plate

Fig. 5. The test block welded into the test plate (a) before welding, (b) after welding.

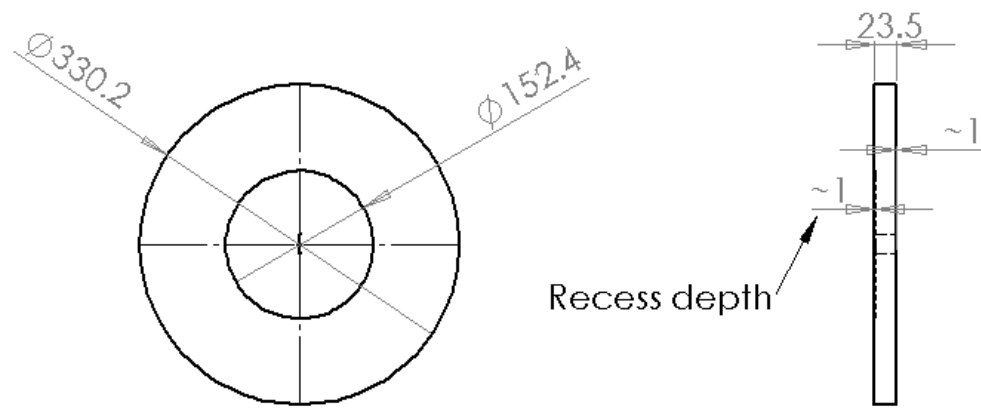

Scale: $1: 5$

All dimensions in $\mathrm{mm}$

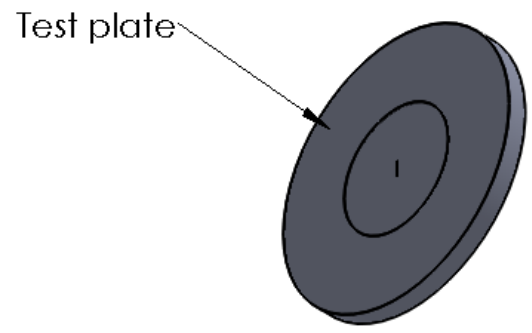

Fig. 6. Detailed dimensions of the test plate.

\section{$4 \quad 2.2$ Experimental procedure}

5 In the JT experiment, high pressure gas was allowed to leak through the crack in the test plate

6 by tapping the high pressure gas into the pressure vessel. During the test, the valves and

7 regulators on the argon gas cylinders were fully opened to pressurize the pressure vessel. The

8 digital pressure gauge with a relative accuracy of $1 \%$ connected to the side nozzle of the pressure 
1 vessel monitored and recorded the pressure inside the pressure vessel. Temperature in the 2 vicinity of the crack was measured by thermocouples connected to a data logger. Once the

3 temperature stabilized for a while, the vessel was depressurized by closing all valves of gas

4 cylinders. The temperature and pressure data were collected until the metal temperature reached

5 room temperature. In addition, prior to the JT experiment, the surface roughness of the surfaces

6 of crack was measured by the surface metrology to be $38.05 \mu \mathrm{m}$. The crack width (i.e. the crack

7 opening displacement) was measured by feeler gauge to be $0.25 \mathrm{~mm}$.

\subsection{Analysis of tested results}

9 In this experiment, the maximum pressure of argon in the pressure vessel is 91 bar. The 10 temperature changes on the outside surface of test plate (in horizontal direction to the crack line)

11 are shown in Fig. 7. With regard to the tested points on the test plate, H1 is the one near the crack 12 and $\mathrm{H} 10$ is the one far away from the crack. It is found that the temperature rises on the surface 13 of the test plate at the beginning of the experiment are due to the temperature increase of the gas 14 inside the pressure vessel. At the beginning of the experiment, high pressure gas was tapped into 15 the pressure vessel while the leakage was negligible due to the lower pressure inside the pressure 16 vessel. The gas warming effect disappeared after the pressure inside the pressure vessel increases 17 to maximum value. At the same time, the JT cooling effect occurred during gas leaking through 18 the crack began to dominate to cool the surrounding metal. During the temperature stable stage 19 (between $160-400 \mathrm{~s}$ ), the temperature of the metal increases slightly as the pressure in gas 20 supply containers reduces gradually. When the test finished, the gas supply was stopped, the 21 metal temperature near the crack decreased with the sharply reduced pressure in the pressure 22 vessel. 


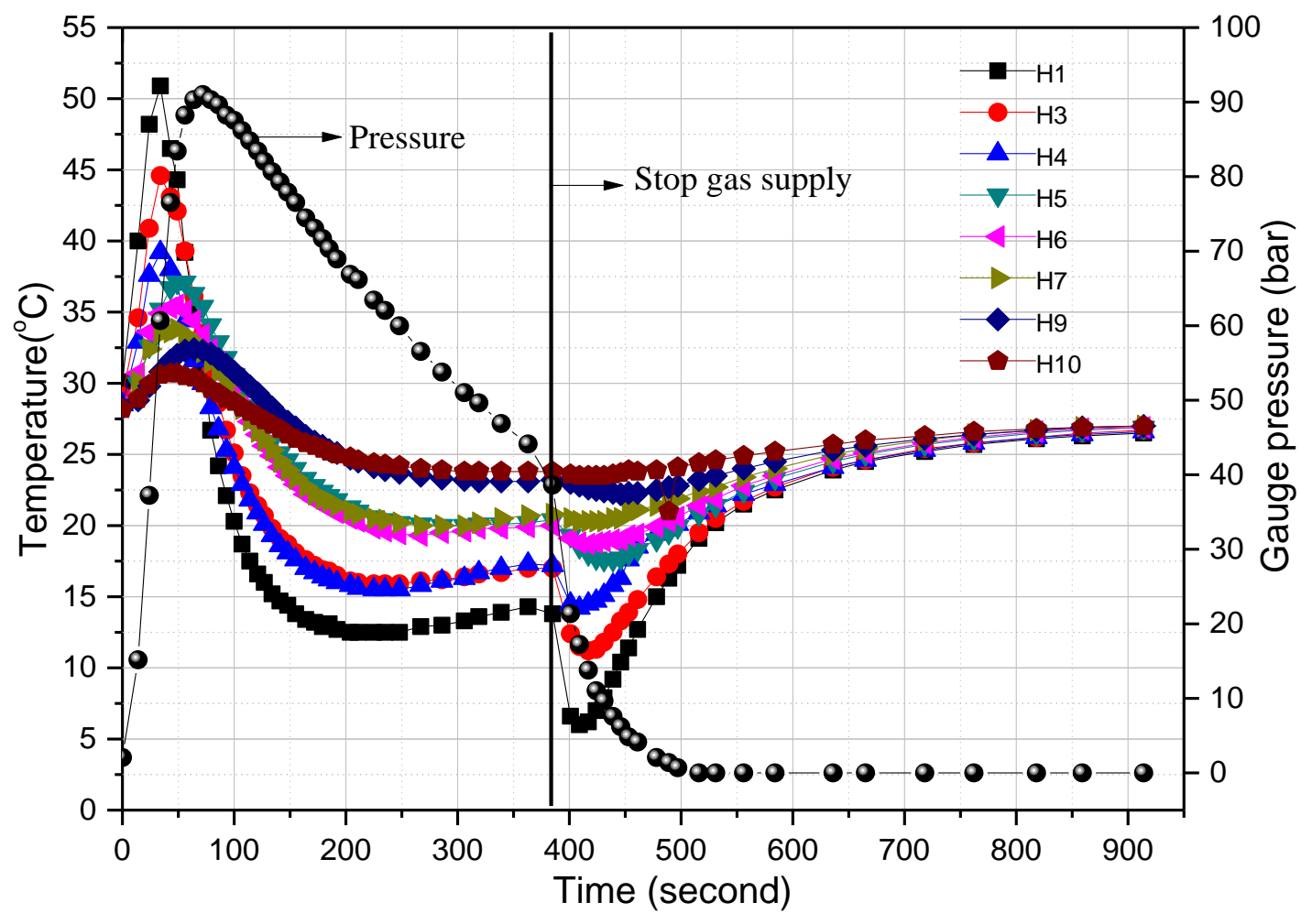

1

2 Fig. 7. Temperature changes in horizontal direction to the crack line on the outside surface of the 3 test plate (the missing $\mathrm{H} 2$ and $\mathrm{H} 8$ refer to the broken thermocouples).

\section{3. Simulation methodology}

Firstly, a crack model with detailed geometry parameters was built to perform the calculation of the pressure loss of leaking gas through a crack and apply JT effect to the gas

7 leakage through the crack. The temperature and heat transfer coefficient of the leaking gas were 8 then calculated by employing MATLAB iterative program to assist the heat transfer simulation 9 between leaking gas and metal in the vicinity of the crack in the COMSOL program.

\section{Mathematical modeling}

11 In a real crack, the flow path often deviates from the plane surface and is three dimensional, 12 which is known as tortuosity. Tortuosity increases the distance or path length that the gas will 13 have to travel (shown in Fig. 8). Beck et al. ${ }^{[19]}$ pointed out that the macroscopic tortuosity, as the 14 crack path wanders (as shown in (a) and (c) of Fig. 8), is much less significant than the 
1 microscopic tortuosity arising from the fracture process, provided that the crack faces remain

2 coincident. Therefore, the planar crack model (b) is considered in this research.

Cylinderwall with cracks

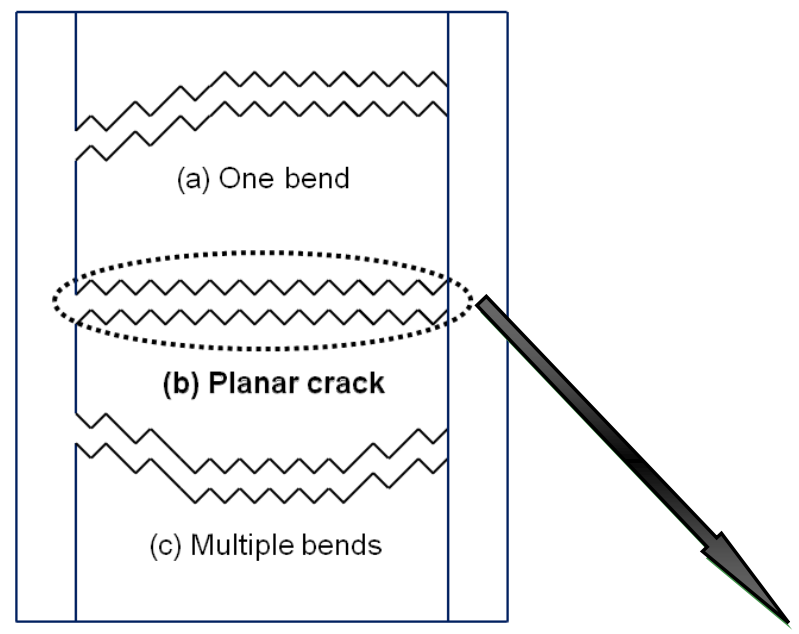

(b) Planar crack

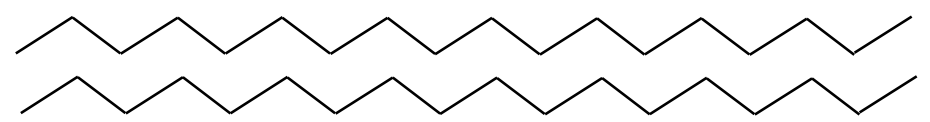

4 Fig. 8. Possible fracture surfaces where sawtooth peaks and valleys represented the roughness 5 and tortuosity is represented by bends in the crack paths (a) with one bend, (b) planar without 6 bends and (c) with multiple bends.

7 After comparison among different models, the model proposed by Taggart et al. ${ }^{[1]}$ is adopted 8 because it is supported by experimental data. ${ }^{[1,19-22]}$ The detailed description of crack geometry is

9 shown in Fig. 9. $\alpha$ is the crack surface angle relative to the crack direction through-wall, $\theta$ is the 10 average flow direction relative to the crack direction through-wall, $W_{\text {ceff }}$ is the effective crack 11 width perpendicular to the average flow direction, $W_{c}$ is the crack opening displacement (or crack 12 width) perpendicular to the through-wall direction, $t$ is the crack through-wall thickness (i.e. 13 crack depth), $t_{\text {eff }}$ is the effective crack through-wall thickness, $R_{\text {local }}$ is the local roughness, $R_{\text {global }}$ 14 is the global roughness, and $R_{\text {glamp }}$ is the peak-to-trough amplitude of the global roughness 15 contours for a sawtooth geometry, equal to four times the global roughness $R_{\text {global. }} W_{1}, W_{2}$ and $W_{3}$ 16 are geometry parameters which are used for the calculation of $W_{\text {ceff. }}$ 


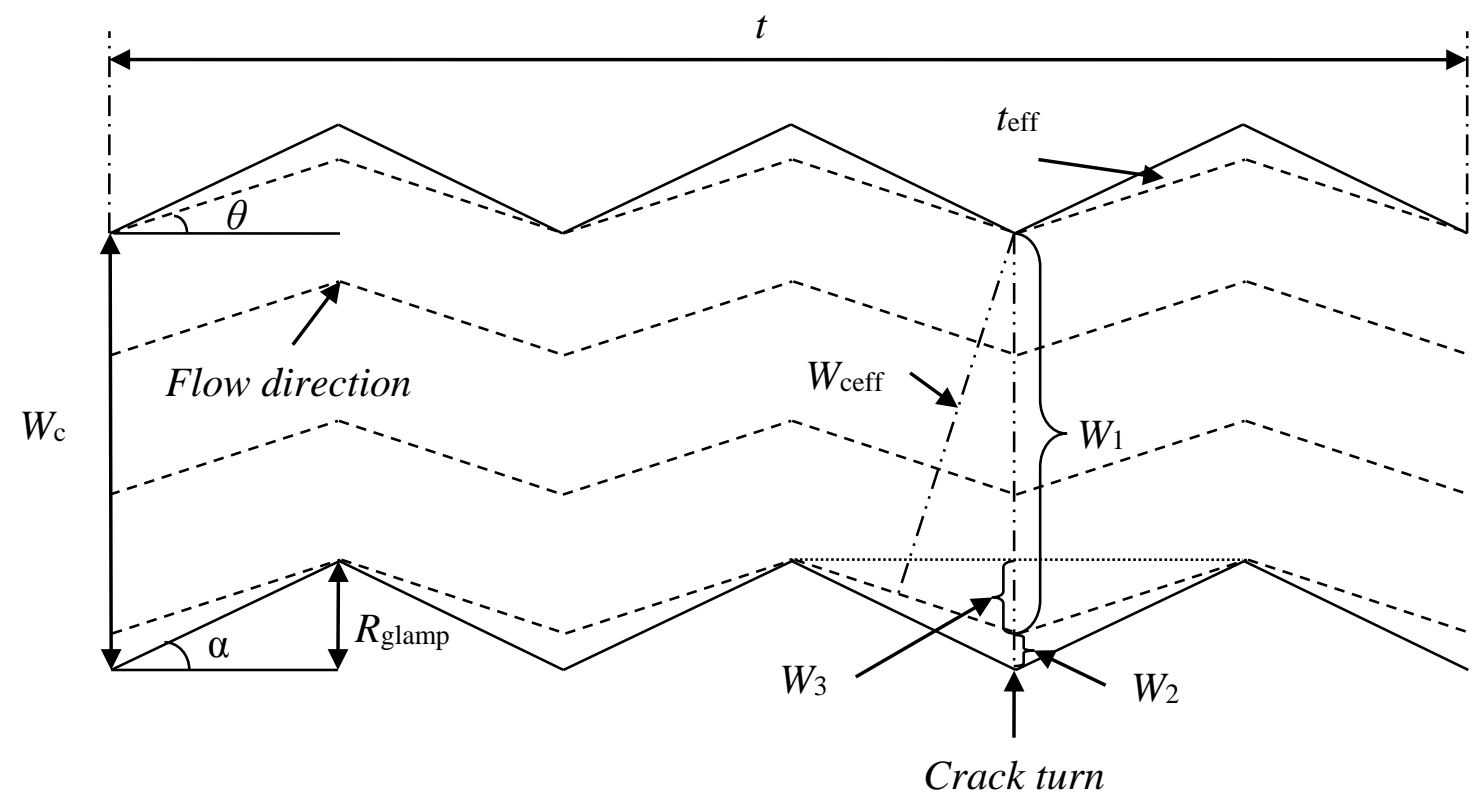

Fig. 9. Detailed schematic of flow around several crack turns.

3 The crack was divided into many equivalent parts along the crack depth direction as shown in 4 Fig. 10. For each increment, the argon gas's pressure, temperature and heat transfer coefficient 5 inside the crack were evaluated by employing the iterative code of MATLAB program as shown 6 in Fig. 11.

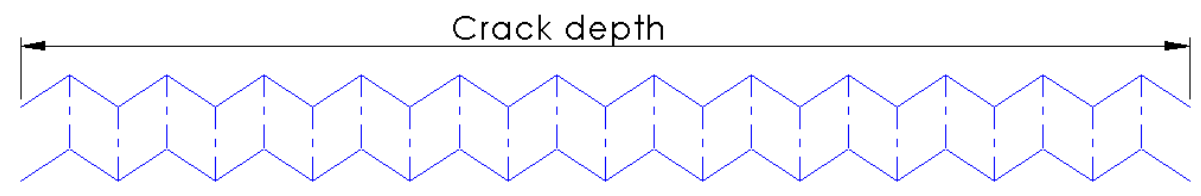

Fig. 10. A model of a crack divided into many equivalent parts. 
(1) Start from the inlet of the crack: define initial gas temperature (T (1)) and pressure (p (1)) (same as experimental condition)

(2) Define crack geometry parameters according to Taggart et al. ${ }^{[1]}$ model as follows:

Crack surface angle, average flow direction, amplitude of global roughess Rglamp, effective roughness Reff, crack through wall thickness teff, crack width Wc, effective crack width Wceff, effective roughness

Reff, and global roughness Rglobal. $R_{\text {eff }}=R_{\text {local }}+c\left(R_{\text {global }}-R_{\text {local }}\right), R_{\text {glamp }}=4 R_{\text {global }}$

(3) Find the pressure change of gas during leaking through the first small part of the crack, which is the sum of pressure drop by frictional loss, inertial loss and recirculation loss:

$\Delta p=\Delta p_{\text {fric }}+\Delta p_{\text {inert }}+\Delta p_{\text {recirc }}$

(4) Calculate the pressure $\boldsymbol{p}$ (2) of gas after leaking through the first small part of the crack

(5) Calculate gas's specific volume $\hat{v}$ (i.e. the reciprocal of density) from the Redlich-Kwong (RK) equation: $p=\frac{R_{\mathrm{con}} T}{\widehat{v}-b^{t}}-\frac{a^{\prime}}{\hat{v}\left(\hat{v}+b^{\prime}\right) T^{0.5}} \quad$ where $a^{\prime}=0.4278 \frac{\mathrm{R}^{2} T_{\mathrm{c}}^{2.5}}{p_{\mathrm{c}}} \quad b^{\prime}=0.0867 \frac{\mathrm{R} T_{\mathrm{c}}}{p_{\mathrm{c}}}$

(6) Find the change of temperature of gas during leaking through the first small part of the crack. $\Delta T=\int_{\mathrm{p}_{1}}^{\mathrm{p}_{2}} \mu_{\mathrm{TT}} \mathrm{d} p$, where Joule-Thomson coefficient $\mu_{\mathrm{JT}}$ is calculated using RK equation:

(7) Calculate the temperature $\boldsymbol{T}$ (2) of gas after leaking through the first small part of the crack

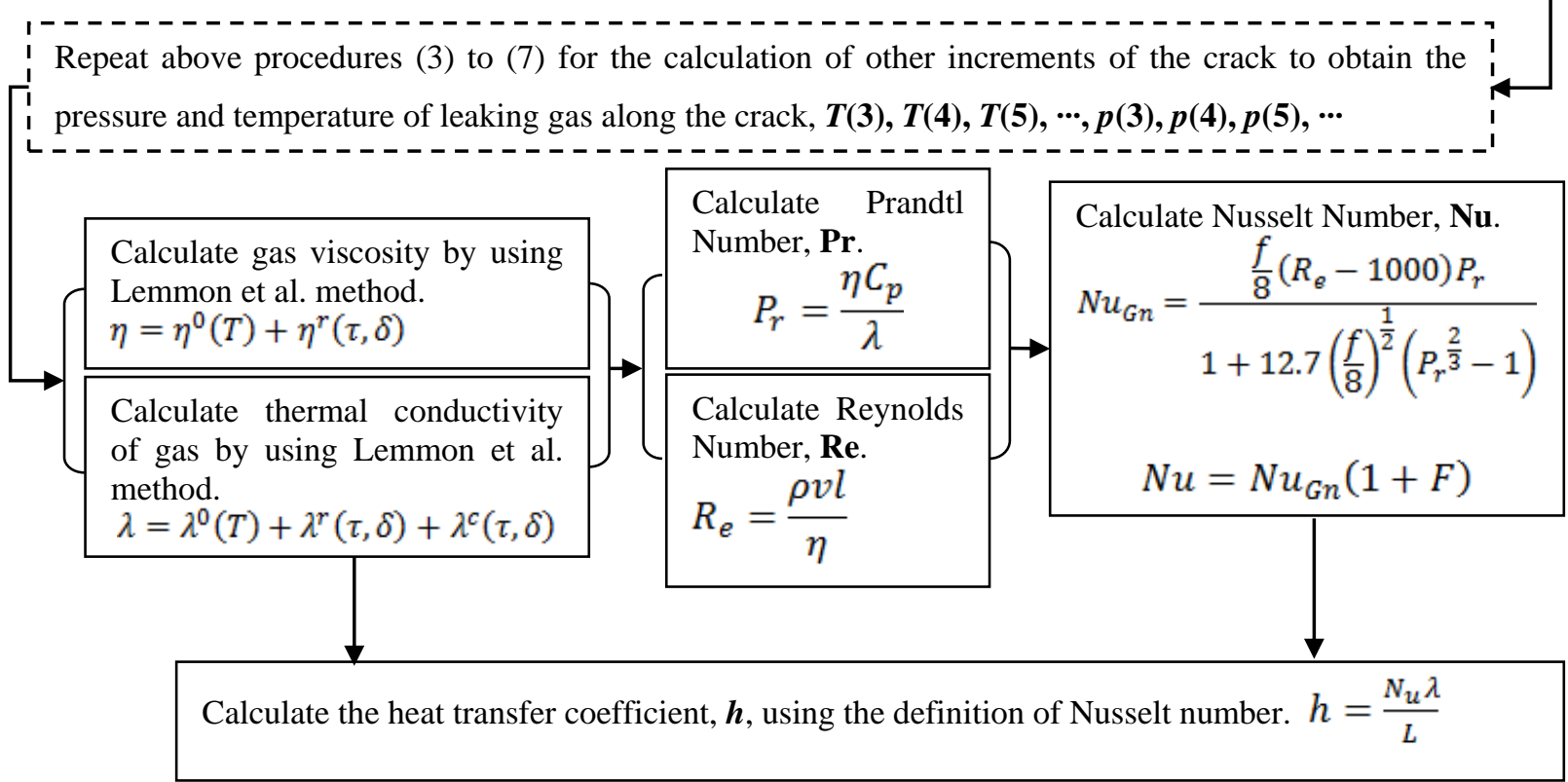

Fig. 11. Calculation flow chart in MATLAB program. 


\section{5. Evaluation of the properties of leaking argon through a crack}

\subsection{Evaluation of the pressure of leaking argon through a crack}

Fluid is forced to pass through the crack by the pressure gradient across the pressure vessel wall during leakage. The pressure dissipation through the crack depends on the flow geometry and effective roughness. The pressure is lost through the crack by three means: friction with crack surface $\Delta p_{\text {fric }}$, inertia pressure $\Delta p_{\text {inert }}$ and the recirculation of the gas $\Delta p_{\text {recirc }}{ }^{[1,19]}$ :

$$
\Delta p=\Delta p_{\text {fric }}+\Delta p_{\text {inert }}+\Delta p_{\text {recirc }}
$$

where $p_{\text {fric }}$ is the frictional term, which is calculated from the friction factor using

$$
\Delta p_{\text {fric }}=\frac{\rho v^{2}}{2} \frac{f t_{\text {eff }}}{2 W_{\text {ceff }}}
$$

where $\rho$ is the fluid density, $v$ is mean leak velocity of the fluid through crack, $f$ is the crack friction factor, $t_{\text {eff }}$ is the effective crack through-wall thickness, $W_{\text {ceff }}$ is the effective crack width perpendicular to the average flow direction. For the calculation of the crack friction factor $f$, the method of Spence et al. ${ }^{[23]}$ gave better agreement with measured results than the use of the relation due to Button et al. ${ }^{[24]}$. Therefore, the method of Spence et al. is adopted to calculate the crack friction factor $f$ in the research and is given as

$$
f=\left[1.82 \log _{10}\left(\frac{W_{\text {ceff }}}{R_{\text {eff }}}\right)-0.77\right]^{-2}
$$

Forces act on the fluid bodies when the flow is undergoing accelerations. These forces are associated with a pressure gradient for which the difference is sometimes known as the inertia pressure. In this case, the effect of inertia pressure loss within the idealized crack arises due to the fluid accelerating around the corners of the crack asperities. Equation (4) describes the inertia pressure loss.

$$
\Delta p_{\text {inert }}=\frac{\rho v^{2}}{2} \frac{2 \mathrm{~N} \theta W_{\text {ceff }}}{W_{\mathrm{C}}}
$$

In Equation (4), $N$ is the actual number of turns in the crack, and $\theta$ is the average flow direction relative to the crack direction through-wall. 
The tortuosity of the zig-zag crack profiles may result in flow separation from the surfaces of

2 the crack. Vortices are created by some of the fluid flowing into the regions of low pressure

3 created by this separation, and the fluid behavior become turbulent in these regions. The flow is

4 at a lower pressure than in the main flow path in these regions. The flow is recirculated

5 producing eddies. This effect can be estimated by the recirculation term in pressure loss, and is

6 given by

$$
\Delta p_{\text {recirc }}=\frac{\rho v^{2}}{2}\left(1-\left(\frac{W_{\text {ceff }}}{W_{c}}\right)^{2}\right)
$$

Fig. 12 shows the pressure distribution of leaking argon through a crack. As is evident from 9 Fig. 12, the pressure of leaking argon drops from 91 bar at the entrance of the crack to 9.5 bar at 10 the exit of the crack. 91 bar is the maximum value of the pressure reached inside pressure vessel 11 during the experiment. The total pressure drop of leaking argon through the crack is 81.5 bar.

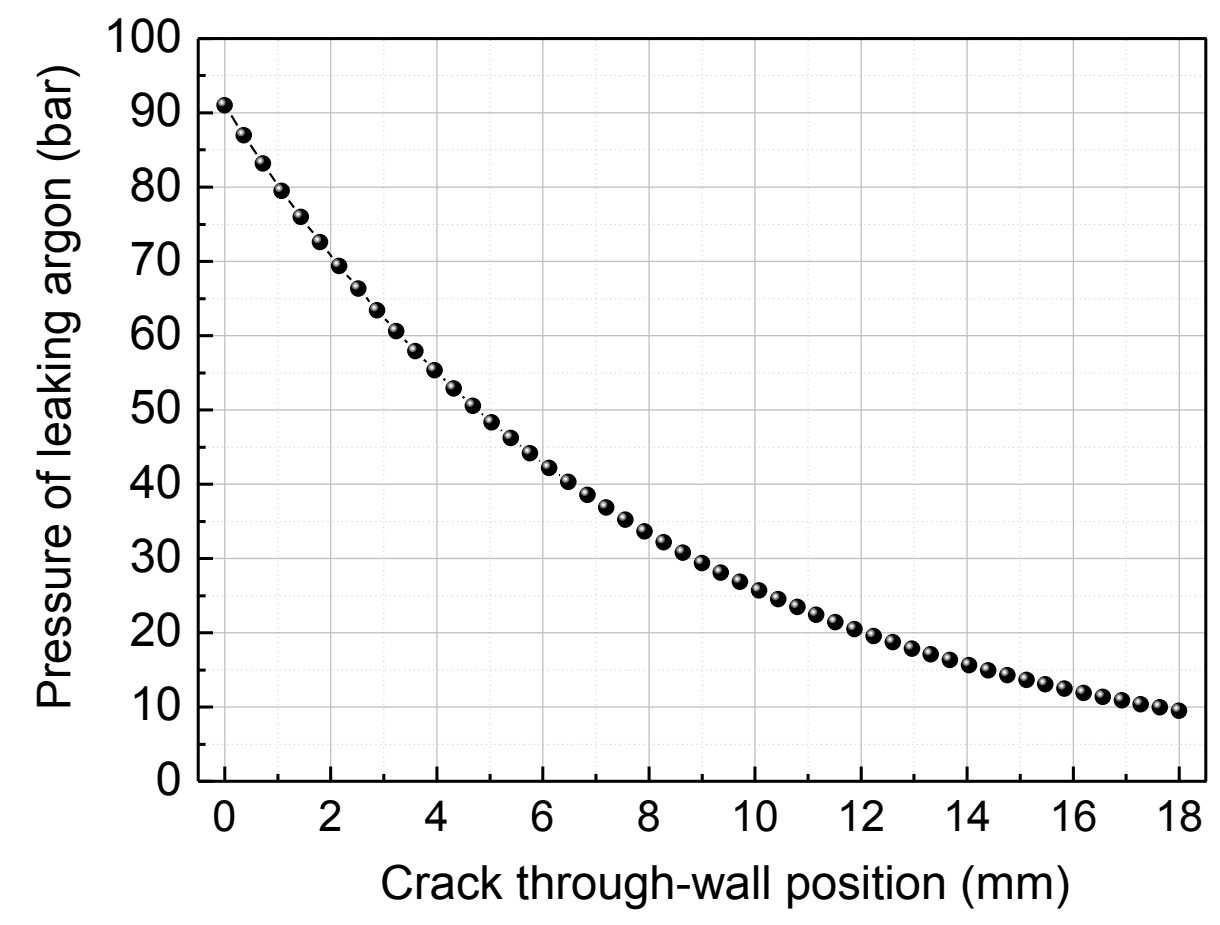

Fig. 12. The pressure of leaking argon through a crack

145.2 Flow velocity evaluation of leaking gas through a crack

15 The mass flow rate can be expressed as 
2 where, $p$ is the fluid pressure inside the vessel

$3 \quad \rho$ is the fluid density inside the vessel

$4 \quad W_{c}$ is the mean width of a crack

$L$ is the a crack length

$C_{\mathrm{D}}$ is the discharge coefficient, and given by

$$
C_{\mathrm{D}}=\frac{1}{1+\sqrt{\mathrm{F}}}
$$

8 where $F$ is the sum of normalized pressure loss terms due to frictional, inertial, and 9 recirculation effects, and is given by Taggart et al. ${ }^{[1]}$

$$
F=F_{\text {fric }}+F_{\text {inert }}+F_{\text {recirc }}
$$

11 where $F_{\text {fric }}$ is the frictional term, $F_{\text {inert }}$ is the inertial term, and $F_{\text {recirc }}$ is the recirculation term:

$$
F_{\text {fric }}=\frac{\mathrm{f} t_{\text {eff }}}{2 W_{\text {ceff }}}
$$

$$
F_{\text {inert }}=\frac{2 \mathrm{~N} \theta W_{\text {ceff }}}{W_{c}}
$$

$$
F_{\text {recirc }}=1-\left(\frac{W_{\text {ceff }}}{W_{c}}\right)^{2}
$$

15 Then flow velocity can be obtained as follows

$$
v=\frac{Q}{\rho A}
$$

17 where $\rho$ is the fluid density in $\mathrm{kg} / \mathrm{m}^{3}$, and $A$ is the cross-section area of a crack. 
2 The JT effect is an isenthalpic process, meaning that the enthalpy of the gas remains constant

3 during the procedure. ${ }^{[25]}$ In thermodynamics, the differential equation of enthalpy is:

$$
d H=C_{p} d T+\left[\hat{v}-T\left(\frac{\partial \widehat{v}}{\partial T}\right)_{p}\right] d p
$$

5 where $H$ is enthalpy, $C_{\mathrm{p}}$ is heat capacity at constant pressure, $T$ is the temperature, $\hat{v}$ is specific volume, $d p$ is the pressure drop per depth increment into the crack.

$7 \quad d H=0$, one can obtain:

$$
\mu_{J T}=\frac{d T}{d p}=\frac{1}{c_{p}}\left[T\left(\frac{\partial \widehat{v}}{\partial T}\right)_{p}-\hat{v}\right]
$$

9 then, the expression of the JT coefficient $\mu \mathrm{JT}$ can be obtained as follows:

$$
\mu_{J T}=\frac{1}{c_{p}}\left[\frac{T}{\rho^{2}} \frac{\left(\frac{\partial p}{\partial T}\right)_{\rho}}{\left(\frac{\partial p}{\partial \rho}\right)_{T}}-\frac{1}{\rho}\right]
$$

11 Partial derivatives $\left(\frac{\partial p}{\partial T}\right)_{\rho}$ and $\left(\frac{\partial p}{\partial \rho}\right)_{T}$ in Equation (15) can be derived from the RK (Redlich-

12 Kwong $)^{[26-28]}$ equation, and then the expression of the JT coefficient $\mu \mathrm{JT}$ can be obtained and 13 given by

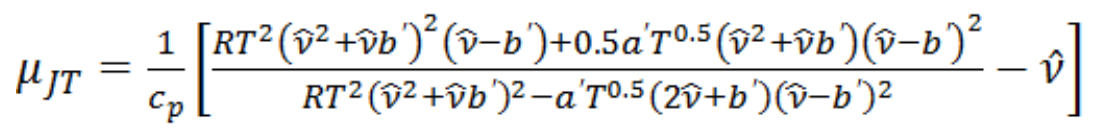

15 where

$$
c_{p}=\frac{a_{0}+a_{1} T+a_{2} T^{2}+a_{3} T^{3}}{M}
$$
$a_{0}, a_{1}, a_{2}, a_{3}$ are empirical constants of gas property dependence, and $M$ is molar mass, $\mathrm{g} / \mathrm{mol}$.

17 Then the temperature drop of the gases can be obtained by employing numerical integrals 18 (using the trapezoidal integration of the MATLAB program) after substituting the formula (16) 19 into the definition formula of $\mu \mathrm{JT}$, as follows:

$$
\Delta T=\int_{\mathrm{p}_{1}}^{\mathrm{p}_{2}} \mu_{\mathrm{JT}} \mathrm{d} p
$$


The temperature distribution of leaking argon through a crack is illustrated in Fig. 13. The 2 temperature of leaking argon decreases from $30{ }^{\circ} \mathrm{C}$ at the entrance of the crack to $-0.04{ }^{\circ} \mathrm{C}$ at the 3 exit of the crack. The total temperature drop of leaking argon through the crack is $30^{\circ} \mathrm{C}$. The 4 fitted temperature formula $T_{\text {inf }}=-2 \times 10^{6} z^{3}+144339 z^{2}-3533.2 z+303.17$ ( $\mathrm{z}$ is the crack

5 depth direction) is used as boundary condition on the crack surface in the subsequent heat 6 transfer simulation.

7 13 with high accuracy is suitable for the evaluation of the heat transfer in a pipe (not in a crack). It

14 is one of the most accurate correlations for a single-phase forced convection, which has a 15 reported accuracy of $\sim 5 \%$ and given by

5.4 Evaluation of heat transfer coefficient of leaking gas through a crack

5.4.1 Petukhov correlation

The heat transfer coefficient is a key input parameter which has to be evaluated and applied 2 in the heat transfer analysis. After a literature survey, it is found that Petukhov correlation ${ }^{[29]}$

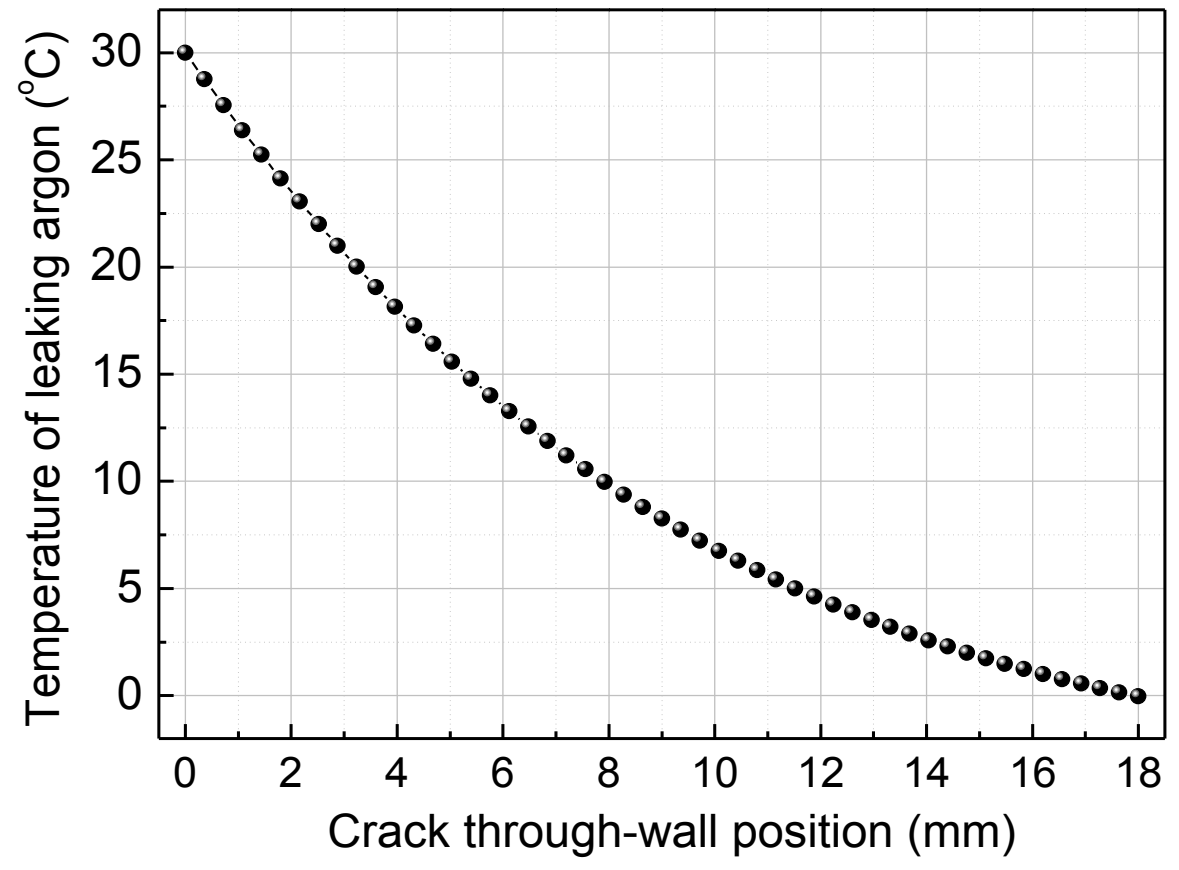

Fig. 13. The temperature of leaking argon through a crack 15 reported accuracy of $\sim 5$ and given by 
$1 \quad$ Nusselt number

$$
N_{u}=\frac{\left(\frac{f}{8}\right) R_{e} P_{r}}{K+12.7\left(\frac{f}{8}\right)^{\frac{1}{2}}\left(P_{r}^{\frac{2}{3}}-1\right)}
$$

2 From the definition formula of Nusselt number $\left(N_{u}\right)$,

$$
N_{u}=\frac{h L}{\lambda}
$$

$4 \quad$ The heat transfer coefficient $(h)$ can be obtained and given by

$$
h=\frac{N_{u} \lambda}{L}
$$

\begin{tabular}{|c|c|c|}
\hline Symbols & Definitions of symbols & Meanings of symbols in definitions \\
\hline$f$ & $\begin{array}{l}f=\left[1.82 \lg \left(\mathrm{R}_{\mathrm{e}}\right)-1.64\right]^{-2} \\
\text { Refer to Adams' paper }{ }^{[30]}\end{array}$ & $R_{e}$ is Reynolds number \\
\hline$R_{e}$ & $R_{e}=\frac{\rho v L}{\eta}$ & $\eta$ is dynamic viscosity in $\mathrm{Pa} \cdot \mathrm{s}$ \\
\hline $\begin{array}{l}P_{r} \text { is Prandtl } \\
\text { number }\end{array}$ & $P_{r}=\frac{\eta C_{p}}{\lambda}$ & $\begin{array}{l}\lambda \text { is thermal conductivity in } \\
\qquad \mathrm{W} /(\mathrm{m} \cdot \mathrm{K})\end{array}$ \\
\hline $\mathrm{K}$ & $K=1.07+\frac{900}{R_{e}}-\frac{0.63}{1+10 P_{r}}$ & - \\
\hline $\begin{array}{l}\qquad L(\mathrm{~m}) \\
\text { Note: the definition }\end{array}$ & \multirow{2}{*}{$L=D_{\mathrm{e}}=\frac{4 A}{P}$} & $D_{\mathrm{e}}$ is the equivalent diameter in $\mathrm{m}$ \\
\hline $\begin{array}{l}\text { shown in Section } \\
5.3 .2\end{array}$ & & $P$ is the wetting perimeter in $\mathrm{m}$ \\
\hline \multirow{3}{*}{$\begin{array}{c}\lambda \\
\text { Note: } \lambda \text { of argon } \\
\text { is evaluated by } \\
\text { employing } \\
\text { Lemmon et al. }{ }^{[31]} \\
\text { method. }\end{array}$} & \multirow{3}{*}{$\lambda=\lambda^{0}(T)+\lambda^{r}(\tau, \delta)+\lambda^{c}(\tau, \delta)$} & $\begin{array}{l}\lambda^{0}(\mathrm{~T}) \text { is the dilute gas thermal } \\
\text { conductivity }\end{array}$ \\
\hline & & $\begin{array}{c}\lambda^{\mathrm{r}}(\tau, \delta) \text { is the residual fluid thermal } \\
\text { conductivity }\end{array}$ \\
\hline & & $\begin{array}{c}\lambda^{c}(\tau, \delta) \text { is the thermal conductivity } \\
\text { critical enhancement }\end{array}$ \\
\hline
\end{tabular}

Definitions and meanings of symbols in Equation (19) and Equation (20) are shown in Table 1.

7 Table 1. Definitions and meanings of symbols in Equation (19) and Equation (20).

9 Reynolds number of the leaking argon through the crack is shown in Fig. 14. It is noticed that 
1 the minimum Reynolds number is $1.4 \times 10^{4}$, and the maximum value of Reynolds number is 1.1 $2 \times 10^{5}$.

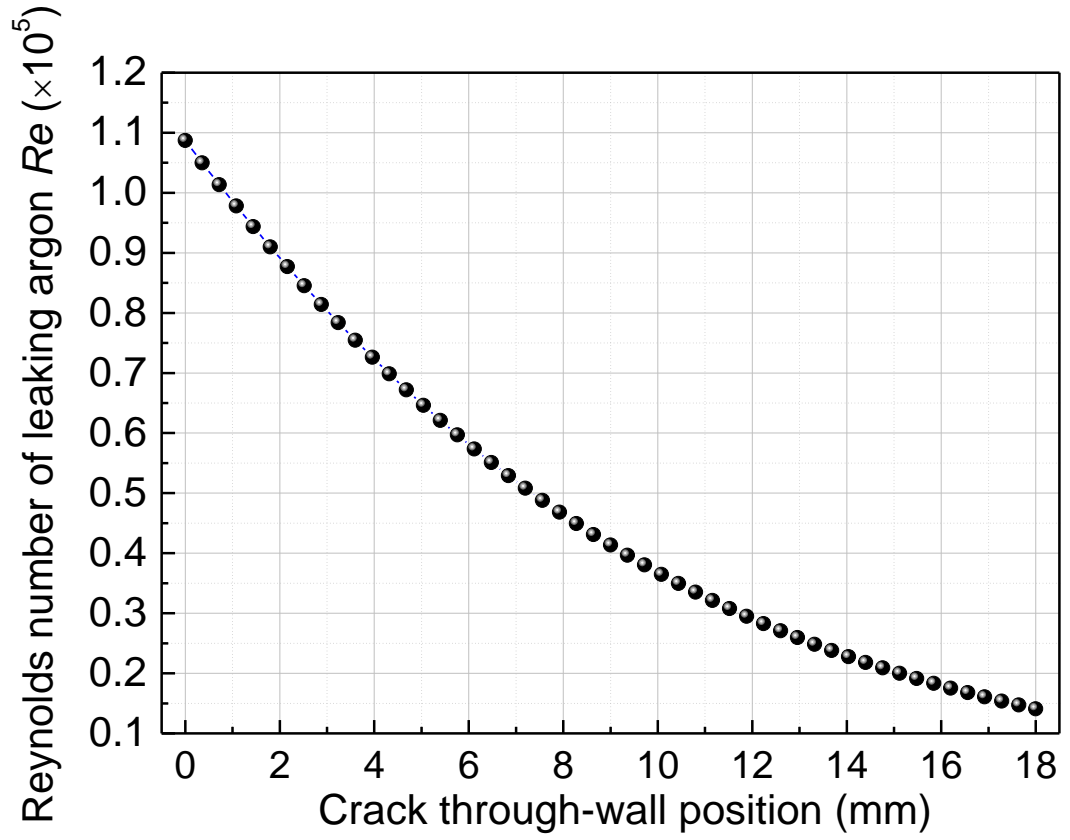

Fig. 14. The Reynolds number of argon leaking through a crack.

5 5.4.2 Extension of the application of Petukhov correlation to microchannels

6 Adams et al. ${ }^{[30]}$ applied Petukhov correlation to microchannels by making some modifications.

7 The microchannels are smaller diameter circular channels with diameters of $0.1-1.09 \mathrm{~mm}$. In

8 current research, the heat transfer occurred in a crack, not in a pipe or a circular channel.

9 Therefore, additional modifications were made to apply Adams et al.'s theory to a crack.

10 (1) Modification of characteristic length in heat transfer equation

11 The correlation of heat transfer can also be applied to non-circular cross-section (e.g. a crack) 12 when the equivalent diameter is used as the characteristic length. ${ }^{[32]}$ The correlation of the 13 equivalent diameter is,

$$
L=D_{\mathrm{e}}=\frac{4 A}{P}
$$


1 where $L$ is characteristic length in $\mathrm{m}, D_{\mathrm{e}}$ is the equivalent diameter in $\mathrm{m}, A$ is the cross-section

2 area of the crack, $\mathrm{m}^{2} ; P$ is the wetting perimeter, m. For a two dimensional crack, $A=l \times W_{c}$,

$3 \quad P=2\left(l+W_{c}\right)$, where $W_{\mathrm{c}}$ is the crack opening displacement and $l \gg W_{c}$, then one can obtain:

$$
L=D_{\mathrm{e}} \approx 2 W_{\mathrm{c}}
$$

(2) Modification of Petukhov correlation to accommodate the small diameters encountered in microchannels

7 Gnielinski ${ }^{[33]}$ modified Petukhov correlation to extend the Reynolds number range down to 8 2300. The Gnielinski correlation is given by

$$
N u_{G n}=\frac{\frac{f}{8}\left(R_{e}-1000\right) P_{r}}{1+12.7\left(\frac{f}{8}\right)^{\frac{1}{2}}\left(P_{r^{\frac{2}{3}}}^{\frac{2}{3}}\right)}
$$

10 where

$$
f=\left(1.82 \log \left(R_{e}\right)-1.64\right)^{-2}
$$

12 Adams et al. ${ }^{[30]}$ modified the Gnielinski correlation to accommodate the small diameters 13 encountered in microchannels by using the following form:

$$
N u=N u_{G n}(1+F)
$$

15 where

$$
F=C R_{e}\left(1-\left(\frac{D}{D_{0}}\right)^{2}\right)
$$

17 where: $C=7.6 \times 10^{-5}, D_{0}=1.164 \mathrm{~mm}, R$ is Reynolds number, $D$ is the diameter of 18 microchannels. In this paper, $D$ denotes the crack width $(W \mathrm{c})$. 


\subsubsection{Evaluation results of heat transfer coefficient of leaking argon through a crack}

2 The heat transfer coefficient of leaking argon through a crack is shown in Fig. 15. It is shown

3 that the heat transfer coefficient of leaking argon will decrease along the crack through-wall

4 position from the inside to the outside of the pressure vessel. The heat transfer coefficient of

5 leaking argon decreases from $6.7 \times 10^{4} \mathrm{~W} /\left(\mathrm{m}^{2} \cdot \mathrm{K}\right)$ at the entrance of the crack to $0.26 \times 10^{4}$

$6 \mathrm{~W} /\left(\mathrm{m}^{2} \cdot \mathrm{K}\right)$ at the exit of the crack. The fitted heat transfer coefficient formula $h=65291 e^{-183 z}$

7 ( $\mathrm{z}$ is the crack depth direction) is used as boundary condition on the crack surface in the 8 subsequent heat transfer simulation.

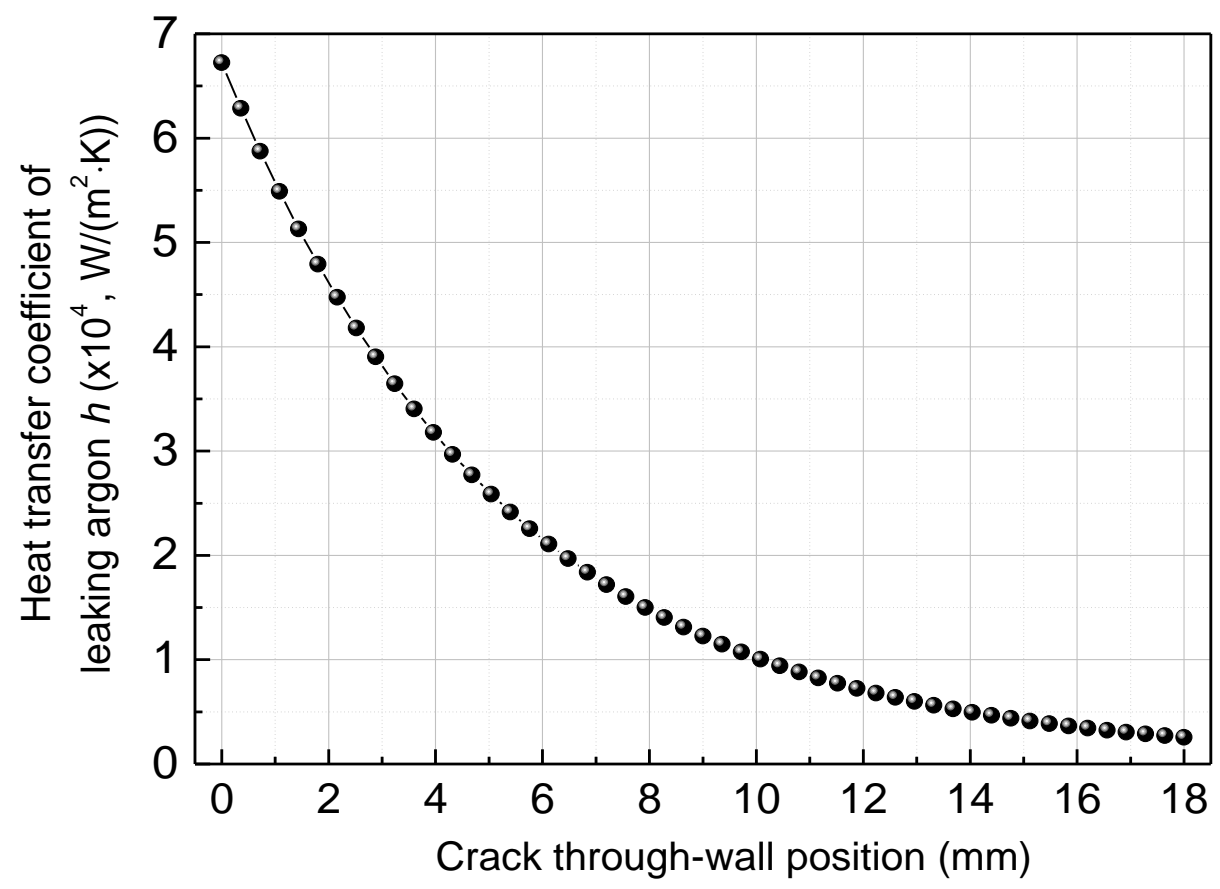

Fig. 15. The heat transfer coefficient of leaking argon through a crack.

\section{6. Simulation of the temperature changes in the test plate}

\subsection{Establishment of mathematical model}

13 A heat transfer application model was developed to simulate the temperature change in the 14 test plate by employing the COMSOL Multiphysics program. The side view of 2D geometry of 15 the test plate with the through-thickness crack is shown in Fig. 16. The material used in this model is Steel AISI 4340 which is a built-in material in COMSOL Materials library, which has 
1 similar properties to that used in the experiment. Due to symmetry conditions, only a 3D quarter 2 model of the test plate is simulated as shown in Fig. 17.

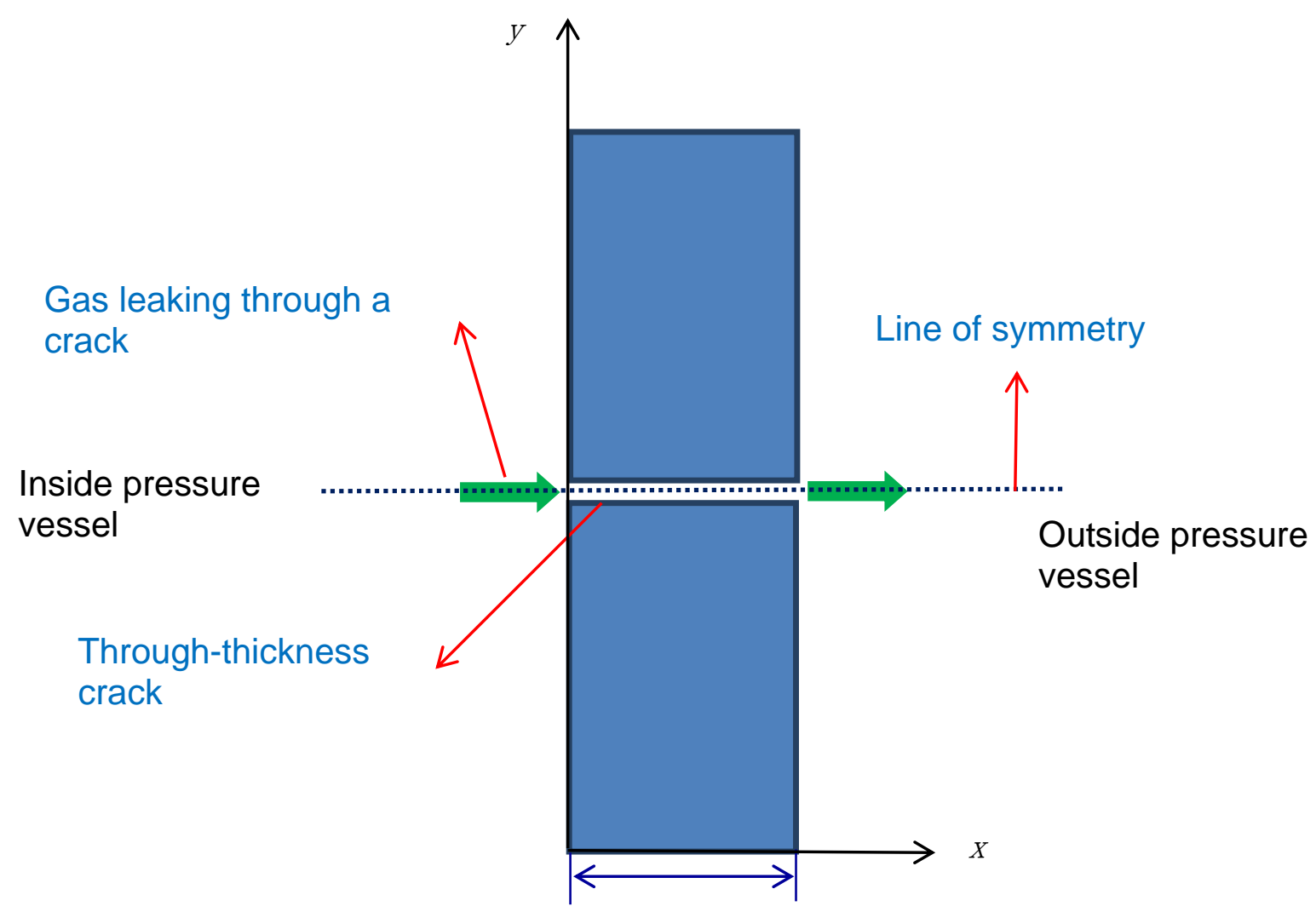

Wall thickness

4 Fig. 16. Diagram of the model of a gas leaking through a crack on the wall of a pressure vessel.

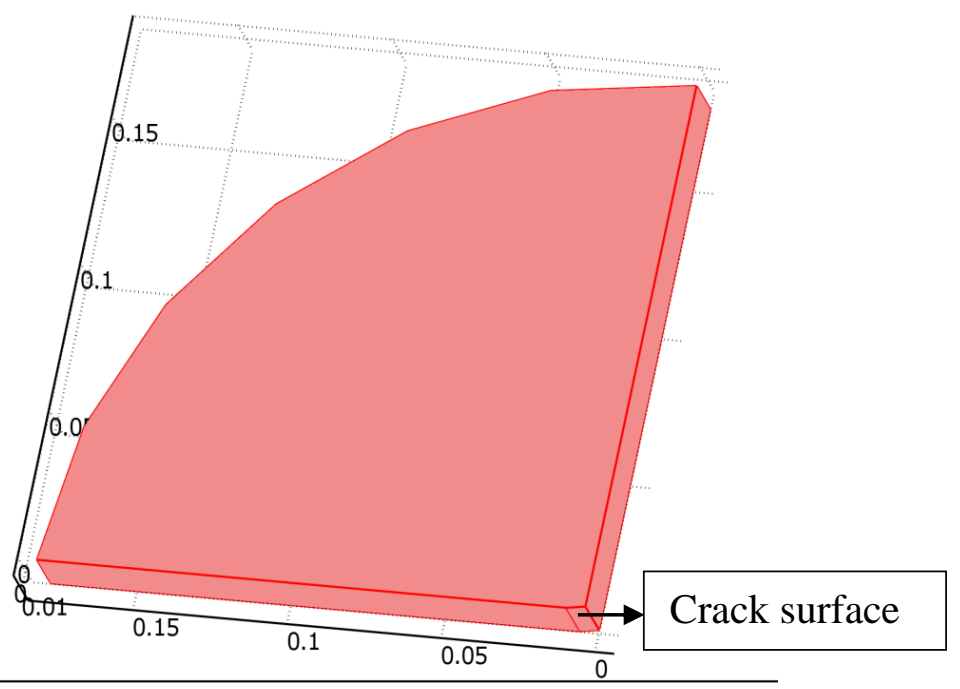

Fig. 17. Quarter model of test plate. 


\subsection{Problem description}

2 As a matter of fact, the heat transfer process between the leaking gas and the surrounding metal under study is a two-way coupling problem (consider both heat transfers from gas to metal

4 and from metal to gas), that is, the leaking gas cool the surrounding metal due to the JT cooling 5 effect, and at the same time, the surrounding metal and atmosphere warm the leaking gas. The leaking gas escapes quickly through the crack to outside the pressure vessel by carrying the heat absorbed from the surrounding metal. Then the new gas will come to the crack from the gas

8 cylinder with same temperature. Gradually, the metal temperature around the crack will drop and approach the temperature of the cold leaking gas. That is to say, the metal will be cooled by the escaping gases in the crack due to the JT cooling effect only if there is enough high pressure gas

11 supply in the cylinder. The continuous high pressure gas supply just acts as "cooling sources" to maintain the low temperature of the gas leaking through the crack. The warming effect from the

13 metal to the gas in the crack depends on the temperature difference between them. It will become

14 negligible when the metal temperature approaches the gas temperature. However, the cooling 15 effect from the gas to the surrounding metal will continue as long as there is enough supply of

16 high pressure gas. For these reasons, the problem treated as a one-way coupling problem (only 17 consider heat transfer from gas to metal) is a reasonable approximation.

\subsection{Governing equations in heat transfer application model}

19 The fundamental law governing all heat transfer is the first law of thermodynamics, commonly referred to as the principle of conservation of energy. However, internal energy, $U$, is a rather inconvenient quantity to measure and use in simulation. ${ }^{[34,35]}$ Therefore, the base law is

22 usually rewritten in terms of temperature, $T$. For a fluid, the resulting heat equation is:

$$
\rho C_{p}\left(\frac{\partial T}{\partial t}+(\mathbf{u} \cdot \nabla) T\right)=-(\nabla \cdot \mathbf{q})+\tau: \mathbf{S}-\left.\frac{T}{\rho} \frac{\partial \rho}{\partial T}\right|_{p}\left(\frac{\partial p}{\partial t}+(\mathbf{u} \cdot \nabla) p\right)+Q
$$

where

- $\quad \mathbf{u}$ is the velocity vector $(\mathrm{m} / \mathrm{s})$

- $\quad \mathbf{q}$ is the heat flux by conduction $\left(\mathrm{W} / \mathrm{m}^{2}\right)$

- $p$ is pressure $(\mathrm{Pa})$

- $\tau$ is the viscous stress tensor $(\mathrm{Pa})$ 
- $\mathbf{S}$ is the strain rate tensor $(1 / \mathrm{s})$ :

$$
\mathbf{S}=\frac{1}{2}\left(\nabla \mathbf{u}+(\nabla u)^{T}\right)
$$

- $Q$ contains heat sources other than viscous heating $\left(\mathrm{W} / \mathrm{m}^{3}\right)$

4 The above heat Equation (28) assumes that mass is always conserved, which means that 5 density and velocity must be related through:

$$
\frac{\partial \rho}{\partial t}+\nabla \cdot(\rho \mathbf{v})=0
$$

7 The heat transfer application mode employed in current study uses Fourier's law of 8 conduction which states that the conductive heat flux, $\mathbf{q}$, is proportional to the temperature 9 gradient:

$$
q_{i}=-k \frac{\partial T}{\partial x_{i}}
$$

11 where $k$ is the thermal conductivity $(\mathrm{W} /(\mathrm{m} \cdot \mathrm{K}))$.

12 Inserting Equation (31) into Equation (28), reordering the terms and ignoring viscous heating 13 and pressure work puts the heat equation on a perhaps more familiar form:

$$
\rho C_{p} \frac{\partial T}{\partial t}+\nabla \cdot(-k \nabla T)=Q-\rho C_{p} \mathbf{u} \cdot \nabla T
$$

15 The heat transfer application mode solves this equation for the temperature, $T$. If the velocity

16 is set to zero, the equation governing pure conductive heat transfer in a solid can be obtained:

$$
\rho C_{p} \frac{\partial T}{\partial t}+\nabla \cdot(-k \nabla T)=Q
$$

\subsection{Initial conditions}

19 Table 2 shows crack geometry parameters and initial state parameters of argon gas inside the

20 pressure vessel same as that in the experiment. The comparison with experimental results 21 performed by Beck et al. ${ }^{[19]}$ indicates that in the absence of proper measurement, the value of $\pi / 6$

22 for crack surface angle is reasonable. And the calculation results in MATLAB are not sensitive to 
1 the value of crack surface angle $(\alpha)$. Therefore, the value of $\pi / 6$ is selected as the crack surface

2 angle.

3 Table 2. Experimental crack geometry parameters and initial state parameters of argon gas inside

4 the pressure vessel.

\begin{tabular}{|c|c|c|}
\hline Input parameters & Description & $\begin{array}{c}\text { Values } \\
\text { (Refer to experiment data) }\end{array}$ \\
\hline$p(1)$ & Initial gas pressure inside the pressure vessel & $91 \mathrm{bar}$ \\
\hline$T(1)$ & Initial gas temperature inside the pressure \\
vessel & $30{ }^{\circ} \mathrm{C}$ \\
\hline$\rho(1)$ & Initial gas density inside a vessel & $149.93 \mathrm{~kg} / \mathrm{m}^{3}$ \\
\hline$W_{\mathrm{c}}$ & Crack width & $0.25 \mathrm{~mm}$ \\
\hline $\mathrm{R}_{\mathrm{global}}$ & Global roughness & $38.05 \mu \mathrm{m}$ \\
\hline$\alpha$ & Crack surface angle & $\pi / 6$ \\
\hline$t$ & Crack depth & $18 \mathrm{~mm}$ \\
\hline
\end{tabular}

\section{$5 \quad 6.5$ Boundary conditions}

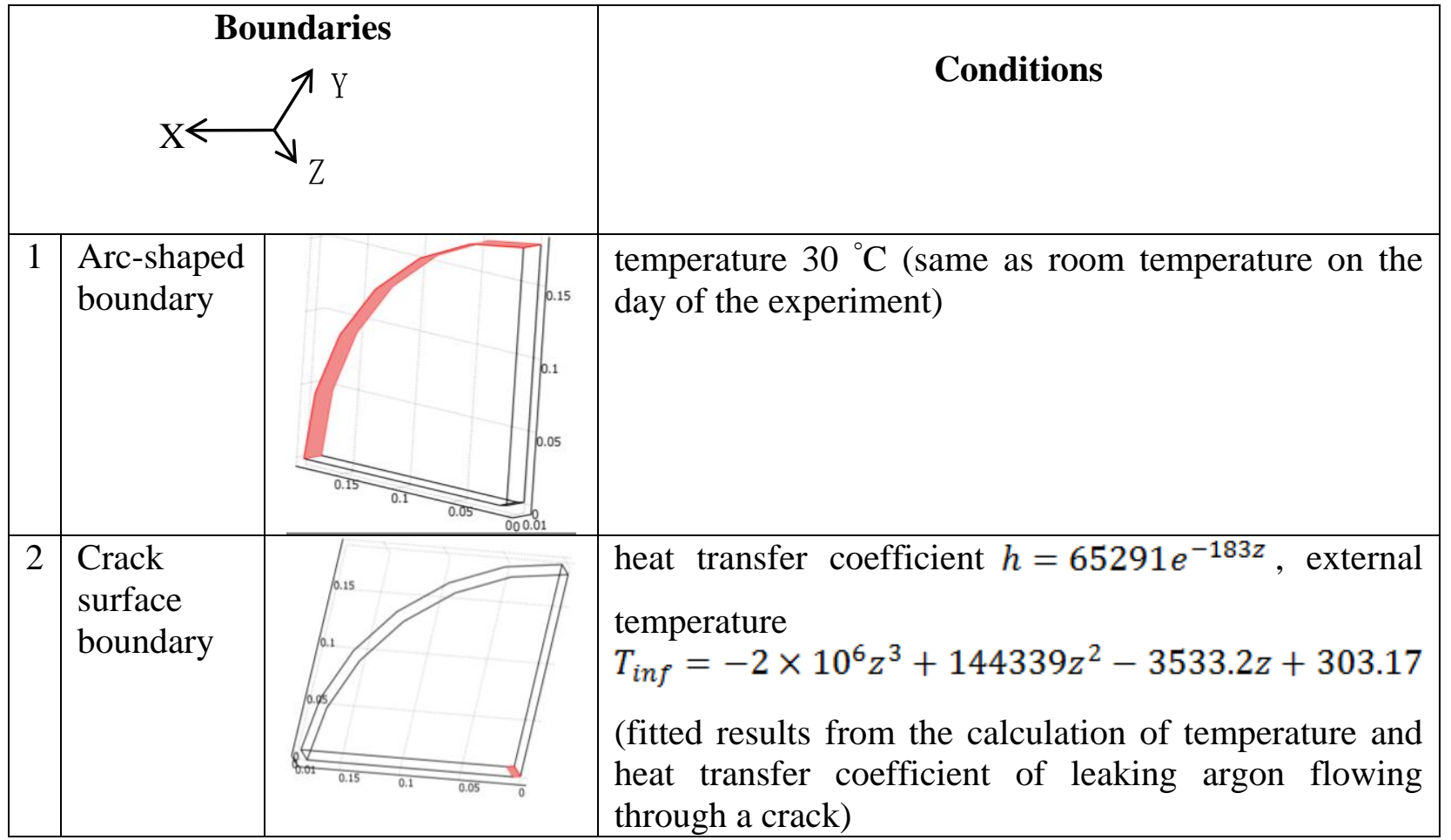




\begin{tabular}{|c|c|c|c|}
\hline \multicolumn{3}{|c|}{$\begin{array}{l}\text { Boundaries } \\
\underbrace{Y}_{Z}\end{array}$} & Conditions \\
\hline 3 & $\begin{array}{l}\text { Inner } \\
\text { surface } \\
\text { boundary } \\
\text { (the surface } \\
\text { of the test } \\
\text { plate } \\
\text { towards } \\
\text { inside of } \\
\text { the } \\
\text { pressure } \\
\text { vessel) }\end{array}$ & & $\begin{array}{l}\text { heat transfer coefficient (selected from heat transfer } \\
\text { coefficients library: external forced convection on a } \\
\text { plate); external temperature } 15^{\circ} \mathrm{C} \text { (gas temperature } \\
\text { inside the pressure vessel during test) }\end{array}$ \\
\hline 4 & $\begin{array}{l}\text { Outer } \\
\text { surface } \\
\text { boundary } \\
\text { (the surface } \\
\text { of the test } \\
\text { plate } \\
\text { towards the } \\
\text { outside of } \\
\text { the } \\
\text { pressure } \\
\text { vessel) }\end{array}$ & & $\begin{array}{l}\text { heat transfer coefficient (selected from heat transfer } \\
\text { coefficients library: external natural convection on a } \\
\text { horizontal plate); external temperature } 30{ }^{\circ} \mathrm{C} \text { (same as } \\
\text { room temperature on the day of the test) }\end{array}$ \\
\hline 5 & $\begin{array}{l}\text { Other } \\
\text { surfaces } \\
\text { boundaries }\end{array}$ & $8.01 \quad 0.15$ & Symmetry \\
\hline
\end{tabular}

3 The results of mesh sensitivity study are shown in Fig. 18. The finite element (FE) meshes of

4 the whole test plate and the close-up on the crack surface are shown in Fig. 19. The element used 5 is a $3 \mathrm{D}$ tetrahedral mesh element with total number of elements of 8122 . The element type is

6 linear Lagrange element with integration order 2. Most of the mesh concentrates on the crack

7 surface to accurately model the temperature changes of the metal in the vicinity of the crack. 


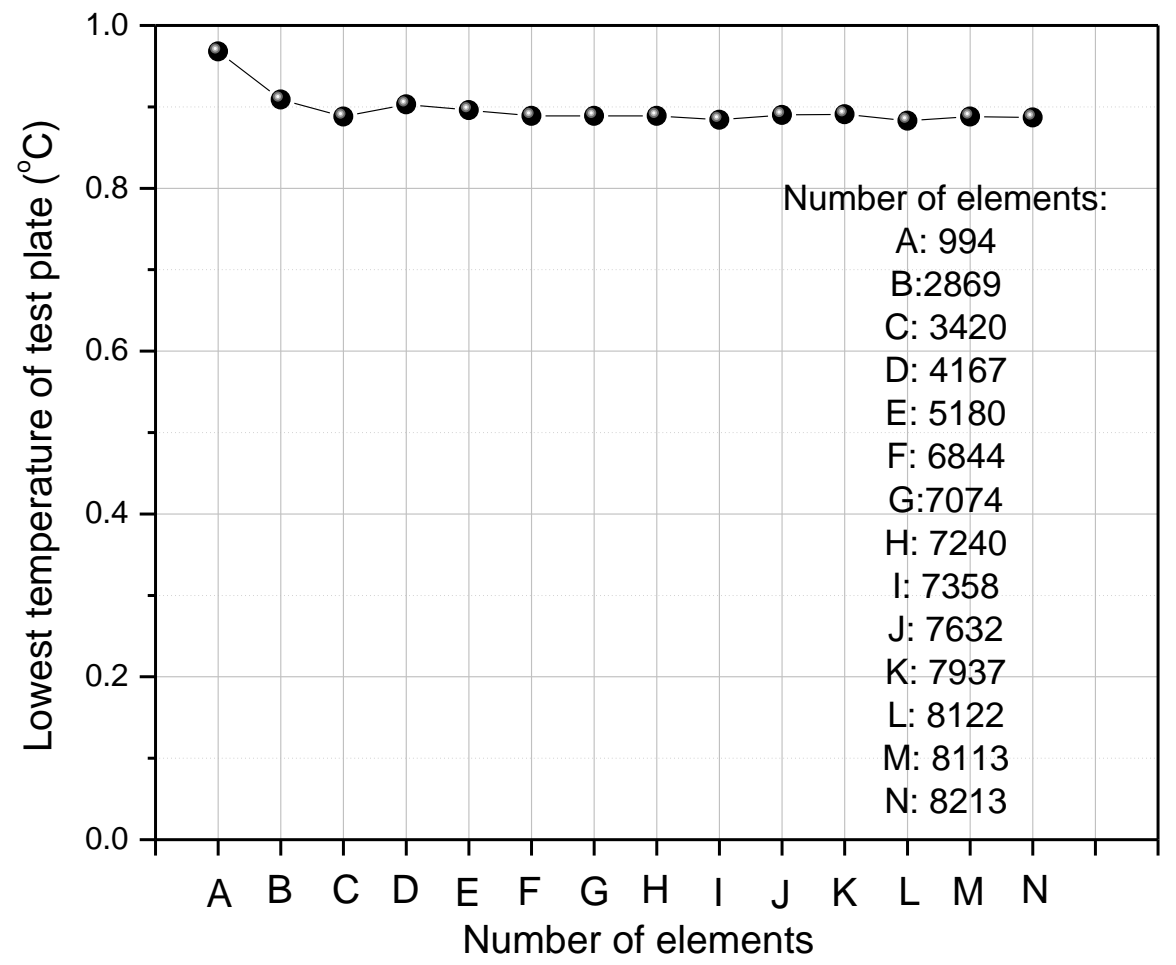

Fig. 18. Calibration of mesh sensitivity.
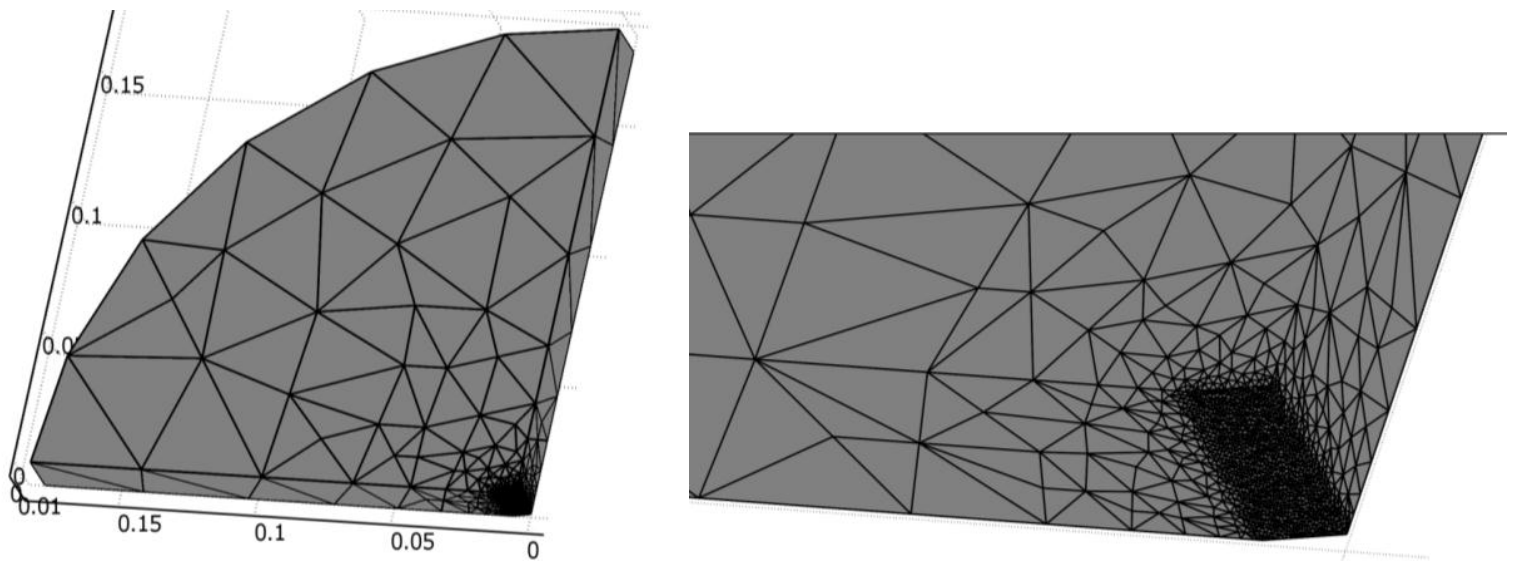

Fig. 19. FE meshes of the test plate.

\section{Simulation results and discussion}

6 Fig. 20 shows the simulated temperature distribution on the test plate. It is noticed that the

7 lowest temperatures in the vicinity of the crack is $13.8{ }^{\circ} \mathrm{C}$. The maximum temperature drop of

8 the test plate from the ambient temperature is $16.2^{\circ} \mathrm{C}$. 


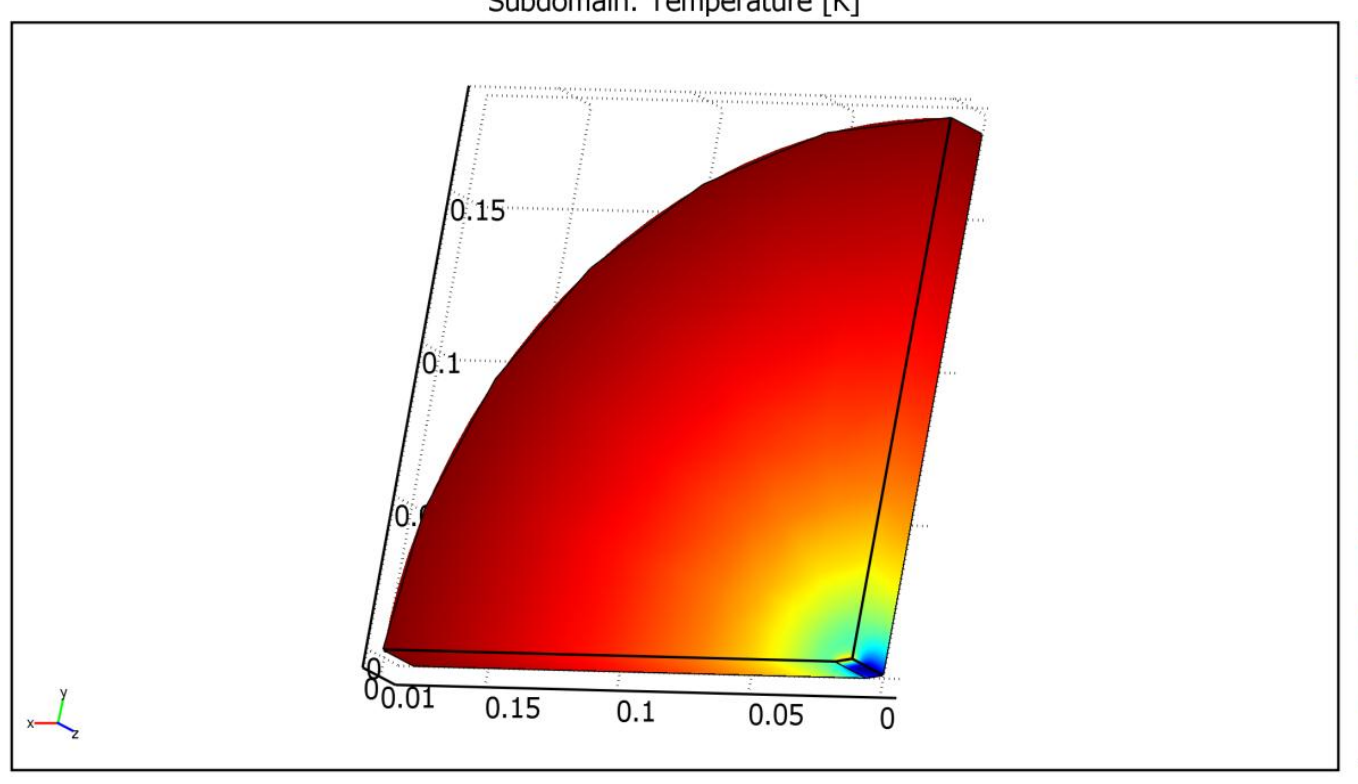

Fig. 20. Simulated temperature distribution on the test plate.

\subsection{Selection of appropriate experimental data for comparison with simulation results}

The lowest metal temperature on the outside surface of the test plate in the diagonal direction to the crack line is lower than that of horizontal direction to the crack as shown in Fig. 21. ${ }^{[11]}$

6 However, there is a depression along the diagonal direction which is caused by the machining 7 process as illustrated in Fig. 22. The temperature results may be affected by the depression in the 8 diagonal direction to the crack line as the leaking gas impacts the depression directly. There are 9 no recesses or defects on the path of the horizontal direction to the crack. Therefore, the 10 temperature results on the outside surface of the test plate in the horizontal direction to the crack 11 line are selected to compare with the simulation results. As shown in Fig. 21 (a), the measured 12 lowest temperature on the outside surface of the test plate (in the horizontal direction to the crack 13 line) during the $\mathrm{JT}$ cooling period is $12.5{ }^{\circ} \mathrm{C}$, and the lowest temperature obtained from 14 simulation is $13.8{ }^{\circ} \mathrm{C}$. It can be concluded that the simulation results agree well with the 15 experimental results on the evaluation of the low temperature in the vicinity of the crack. It 16 should be noticed that the location of the calculated lowest temperature in simulation is not same 17 as that of the tested lowest temperature in this experiment which will be explained in the 18 following section. 


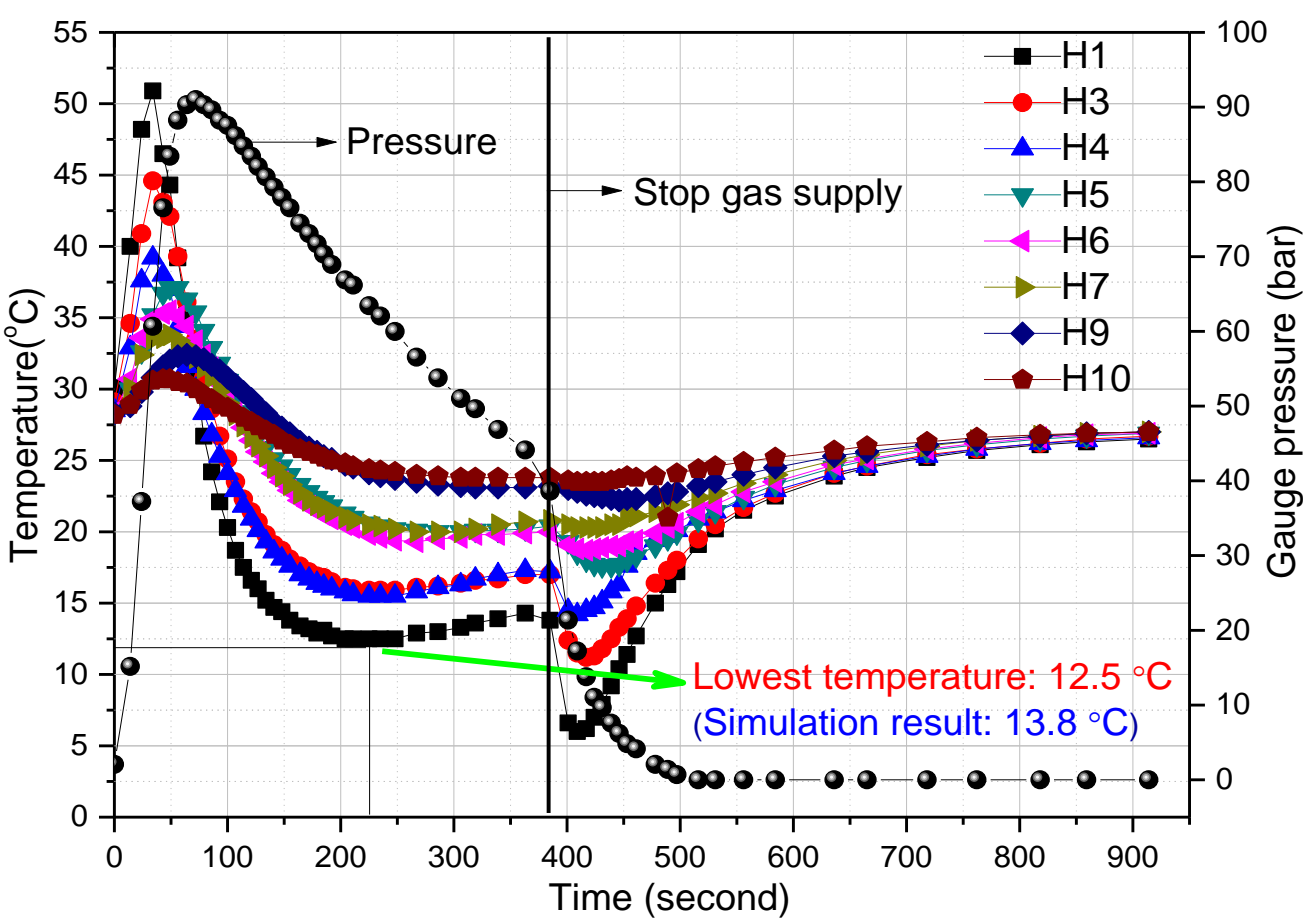

(a) In horizontal direction to the crack line.

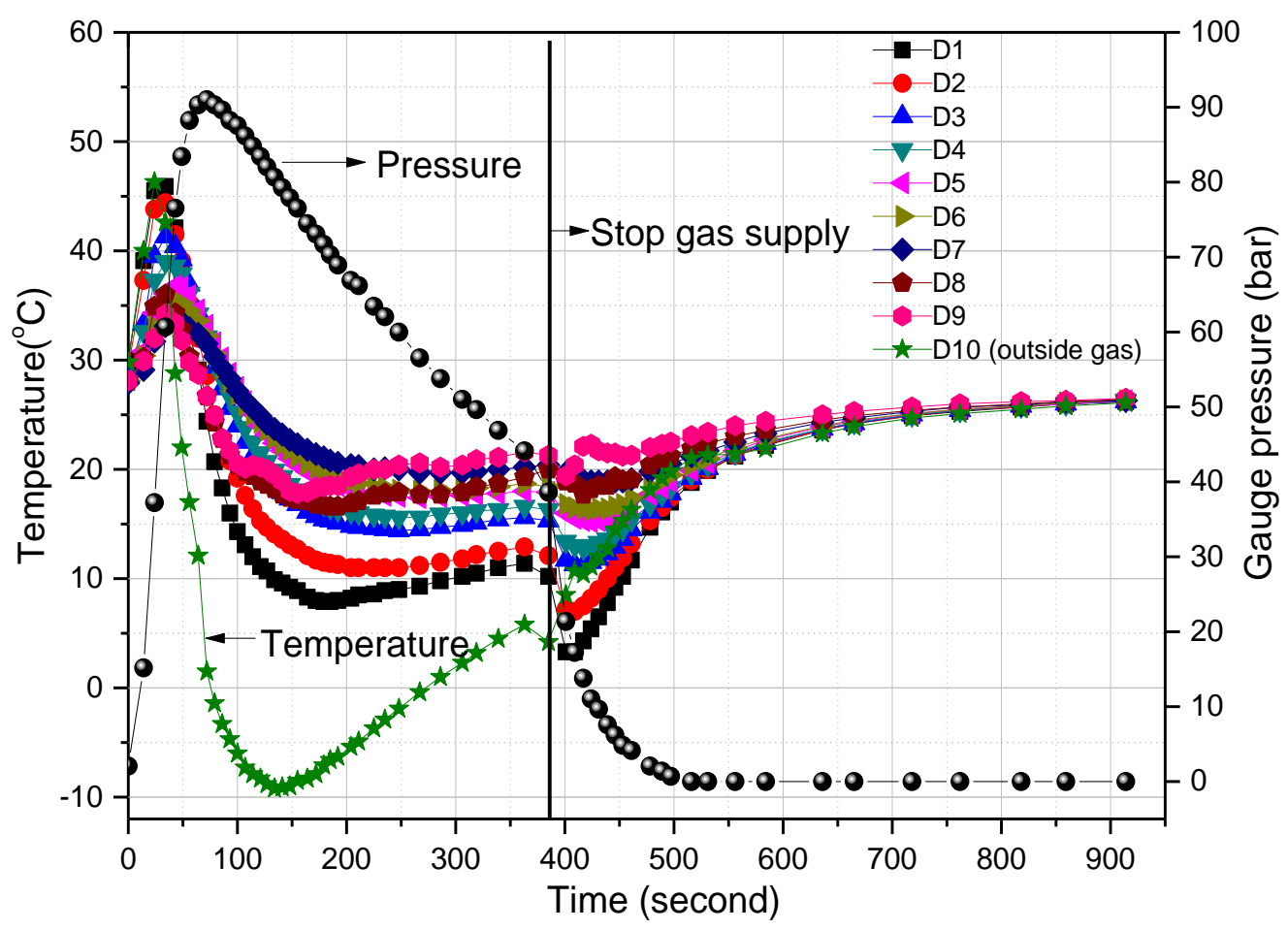

(b) In diagonal direction to the crack line.

Fig. 21. Temperature change on the outside surface of test plate. 


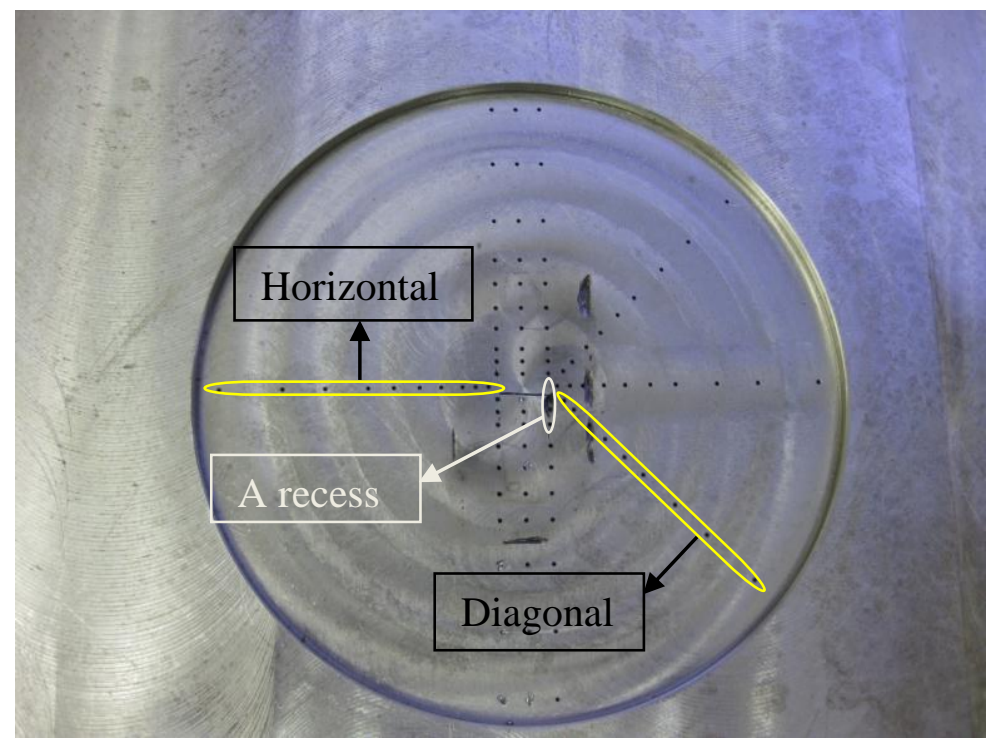

Fig. 22. A recess near the crack on the surface of the test plate.

\subsection{Analysis of results}

4 In Fig. 21 (a), it is noticed that the JT cooling effect decays with the decreasing of the gas 5 pressure inside the containers due to the limited supply of gas which ran out. If there is enough 6 gas source (such as in a long gas pipeline or large vessel) i.e. under the infinite source condition, 7 the JT cooling effect can continue indefinitely. Furthermore if the pressure difference between 8 inside and outside of pressure vessel is kept constant, the pressure induced stresses is maintained 9 to drive the propagation of the crack. In this regard, the JT cooling effect is much more 10 dangerous for larger pressure vessels or pipeline with a large volume of gas.

11 Reepmeyer et al. ${ }^{[36]}$ have carried out several hydraulic full scale fatigue tests to test the JT 12 effect during leakage in accordance with the requirements in Det Norske Veritas (DNV) rules for 13 CNG carriers (carrying pressure vessels of $250 \mathrm{bar}$ ). The lowest temperature close to the exit of 14 the crack during leakage was around $-70{ }^{\circ} \mathrm{C}$ at the steel surface. They stated that temperatures 15 below $-35{ }^{\circ} \mathrm{C}$ can result in the embrittlement of the X80 pipeline steel. From the inspection of 16 the fracture, however, no evidence was found for a brittle crack growth during the cooling down 17 test. Therefore, it is not appropriate to evaluate the severity of the impact of the JT cooling effect 18 on the reliability of pressure vessels based on the lowest temperature on the crack surface as the 19 area of extreme low temperature is very small due to the localized cooling effect. In addition, it 
1 takes enough time to create a significant volume of material at low temperature as the heavy

2 cylinder wall acts as a large heat buffer. In comparison, the lowest temperature simulated in this

3 paper is more useful as it predicts the temperature located at a certain distance from the crack

4 (the yellow circle as shown in Fig. 23).

5 The heat transfer among leaking gas, test plate and surrounding environment would 6 eventually result in a significant temperature gradient on the test plate. According to previous 7 report $^{[11]}$, the temperature distribution on the test plate is radial direction dependent, the 8 temperature change in horizontal and diagonal direction to the crack line has a similar trend. The 9 sharp temperature gradient will cause tensile thermal stresses with a tendency to open the crack 10 further at the crack tip which coincides with the highest temperature gradient. If the lowest 11 temperature obtained at the circle location in Fig. 23 is below materials' embrittlement 12 temperature, then the temperature of materials inside the rectangular area will drop to much 13 lower temperature than that at the location of the lowest temperature test point. Then, the whole 14 low-temperature region in the vicinity of the crack may trigger the transition of previously stable 15 crack propagation to rapid unstable growth and affect the validity of LBB principle. Therefore, it 16 is necessary to carry out further studies about the JT cooling effect during leakage to increase the 17 safety and reliability of pressure vessels, especially the pressure vessels storing or transporting 18 gas under higher pressure located in cold regions.

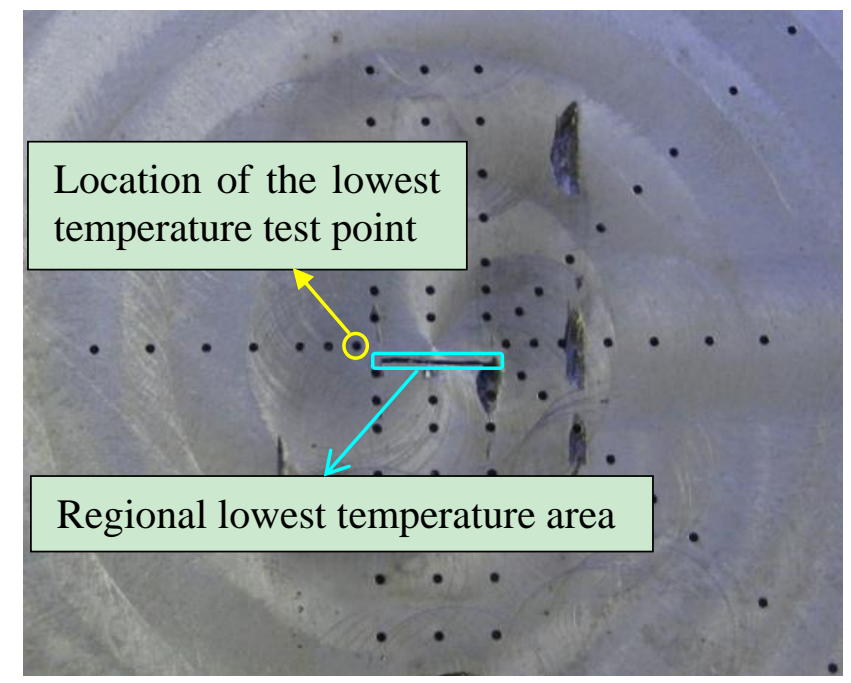

Fig. 23. Location of the lowest temperature test point 
2 In this paper, a two-stage simulation method is proposed to simulate the heat transfer of high 3 pressure argon leaking through a narrow crack to identify the impact of the JT cooling effect

4 occurred during leakage. The first stage is the properties evaluation of the leaking argon through

5 a crack by using MATLAB program followed by the second stage which is the temperature

6 simulation of the test plate by employing the heat transfer model in the COMSOL Multiphysics 7 program.

8 The calculated pressure of leaking argon drops from 91 bar at the entrance of the crack to 9.5 9 bar at the exit of the crack. The lowest temperature of the test plate in the vicinity of the crack 10 obtained from the simulation is $13.8^{\circ} \mathrm{C}$. There is a good agreement between the simulation and 11 experiment at the obtained lowest temperature in the test plate. The lowest temperature obtained 12 from the proposed method predicts the temperature located at a certain distance (regional cooling) 13 from the crack in the experiment. Compared with the localized cooling, the regional cooling is 14 likely to affect the validation of LBB approach. Therefore, the proposed two-stage simulation 15 method is a useful tool for predicting the regional lowest temperature and paving the way for the 16 further study of the JT cooling effect during leakage. 


\section{REFERENCES}

[1] J.P. Taggart, P.J. Budden, Leak before break: Studies in support of new R6 guidance on leak rate evaluation, J. Press Vessel Technol. 130 (2008) 0114021-0114026.

[2] Y.F. Makogon, S.A. Holditch, T.Y. Makogon, Natural gas-hydrates - A potential energy source for the 21st Century, J. Petrol. Sci. Eng. 56 (2007) 14-31.

[3] M.J. Economides, D.A. Wood, The state of natural gas, J. Nat. Gas Sci. Eng. 1 (2009) 113.

[4] D. Karasalihovic, L. Maurovic, S. Sunjerga, Natural gas in croatia's energy-future, Appl. Energ. 75 (2003) 9-22.

[5] G. Wilkowski, Leak-before-break: What does it really mean?, J. Press Vessel Technol. 122 (2000) 267-272.

[6] M.L. Vanderglas, Experiences using three-dimensional finite element analysis for leakbefore-break assessment, Int. J. Pres. Ves. Pip. 43 (1990) 241-253.

[7] N.S. Huh, Y.J. Kim, J.B. Choi, C.R. Pyo, Prediction of failure behavior for nuclear piping using curved wide-plate test, J. Press Vessel Technol. 126 (2004) 419-425.

[8] W. Kastner, E. Röhrich, W. Schmitt, R. Steinbuch, Critical crack sizes in ductile piping, Int. J. Pres. Ves. Pip. 9 (1981) 197-219.

[9] C. Wüthrich, Crack opening areas in pressure vessels and pipes, Eng. Fract. Mech. 18 (1983) 1049-1057.

[10] P.C. Paris, H. Tada, The application of fracture proof design methods using tearing instability theory to nuclear piping postulating circumferential throughwall cracks, NUREG/CR-3464, US Nuclear Regulatory Commission, September (1983)

[11] G. Ai, H.W. Ng, An experimental study on the Joule-Thomson cooling effect on metal temperatures in the vicinity of a leaking through-wall crack in a pressure vessel, Int. J. Pres. Ves. Pip. (2014 (submitted))

[12] E.S. Burnett, Experimental study of the joule-thomson effect in carbon dioxide, Physical Review 22 (1923) 590-616.

[13] J.R. Roebuck, H. Osterberg, The Joule-Thomson effect in argon, Physical Review 46 (1934) 785-790. 
[14] J.R. Roebuck, H. Osterberg, The Joule-Thomson effect in helium, Physical Review 43 (1933) 60-69.

[15] O.C. Bridgeman, The Joule-Thomson effect and heat capacity at constant pressure for air, Physical Review 34 (1929) 527-533.

[16] J.H. Perry, C.V. Herrmann, The Joule-Thomson effect of methane, nitrogen, and mixtures of these gases, J. Phys. Chem. 39 (1935) 1189-1195.

[17] ASME Boiler and Pressure Vessel Code. Section II. Part D. 1995, The American Society of Mechanical Engineers: New York.

[18] ASME Boiler and Pressure Vessel Code. Section VIII. Division 1. 1998, The American Society of Mechanical Engineers: New York.

[19] S.B.M. Beck, N.M. Bagshaw, J.R. Yates, Explicit equations for leak rates through narrow cracks, Int. J. Pres. Ves. Pip. 82 (2005) 565-570.

[20] T.C. Chivers, The influence of surface roughness on fluid flow through cracks, Fatigue and Fracture of Engineering Materials and Structures 25 (2002) 1095-1102.

[21] L.V. Clarke, H. Bainbridge, S.B.M. Beck, J.R. Yates, Measurement of fluid flow rates through cracks, Int. J. Pres. Ves. Pip. 71 (1997) 71-75.

[22] D.L. Rudland, G. Wilkowski, P. Scott, Effects of crack morphology parameters on leakrate calculations in LBB evaluations, Int. J. Pres. Ves. Pip. 79 (2002) 99-102.

[23] G.S.M. Spence, J. Wilkinson, R.F. Chandler, Leakage flow through small cracks-Report of second stage of experimental work, (1991).

[24] B.L. Button, A.F. Grogan, T.C. Chivers, P.T. Manning, Gas flow through cracks, J Fluids Eng Trans ASME 100 (1978) 453-458.

[25] F. Reif, Chapter 5-Simple applications of macroscopic thermodynamics. Fundamentals of Statistical and Thermal Physics. 1965, New York: McGraw-Hill.

[26] O. Redlich, J.N.S. Kwong, On the thermodynamics of solutions. V: An equation of state. fugacities of gaseous solutions, Chem. Rev. 44 (1949) 233-244.

[27] S. Peng, J. Chen, J. Yang, Calculation for temperature drop induced by adiabatic throttle of natural gas (in Chinese), Gas \& Heat 26 (2006) 1-4.

[28] J.W. Murdock, Fundamental fluid mechanics for the practicing engineer. 1993, New York: M. Dekker. 
[29] B.S. Petukhov, V.A. Kurganov, A.I. Gladuntsov, Heat transfer in turbulent pipe flow of gases with variable properties, Heat Transfer -Sov Res 5 (1973) 109-116.

[30] T.M. Adams, S.I. Abdel-Khalik, S.M. Jeter, Z.H. Qureshi, An experimental investigation of single-phase forced convection in microchannels, Int. J. Heat Mass. Tran 41 (1998) 851-857.

[31] E.W. Lemmon, R.T. Jacobsen, Viscosity and thermal conductivity equations for nitrogen, oxygen, argon, and air, Int. J. Thermophys. 25 (2004) 21-69.

[32] J.H. Lienhard(IV), J.H. Lienhard(V), A heat transfer textbook. $3^{\text {rd }}$ ed. 2008, Cambridge, Massachusetts, U.S.A.: Phlogiston Press.

[33] V. Gnielinski, New equations for heat and mass transfer in turbulent pipe and channel flow, International Chemical Engineering 16 (1976) 359-368.

[34] F.P. Incropera, D.P. DeWitt, Fundamentals of heat and mass transfer. $4^{\text {th }}$ ed. 1996: John Wiley \& Sons.

[35] A. Bejan, Heat transfer. 1993: Wiley.

[36] O. Reepmeyer, P. Lothe, S. Valsgard, M. Erdelen-Peppler, G. Knauf. Full scale gas leak test at a large diameter X-80 DSAW pipe, in Proceedings of the ASME International Pipeline Conference 2006. Calgary, Alberta, Canada. 